This article should be cited as: Mahdi Sharifzadeh, Raymond Khoo Teck Hien, Nilay Shah. China's roadmap to low-carbon electricity and water: Disentangling greenhouse gas (GHG) emissions from electricity-water nexus via renewable wind and solar power generation, and carbon capture and storage. Applied Energy Volume 235, 1 February 2019, Pages 31-42. https://doi.org/10.1016/j.apenergy.2018.10.087 (Link)

\title{
China's Roadmap to Low-Carbon Electricity and Water: disentangling Greenhouse Gas (GHG) emissions from Electricity- Water Nexus via Renewable Wind and Solar Power Generation, and Carbon Capture and Storage
}

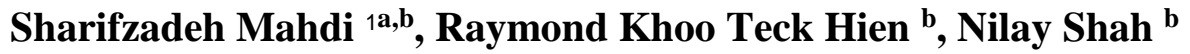 \\ ${ }^{a}$ Department of Electronic and Electrical Engineering, University College London, London, WC1E 7JE, United Kingdom. \\ ${ }^{\mathrm{b}}$ Centre for Process Systems Engineering (CPSE), Department of Chemical Engineering, Imperial College London, London SW7 \\ 2AZ, United Kingdom.
}

\begin{abstract}
Electricity and water form an intricate nexus, in that water is crucial for power generation, and electricity (or other primary forms of energy) is the key enabler for water purification and waste-water treatment. Nonetheless, both energy conversion and water purification result in substantial amounts of greenhouse gas (GHG) emissions. These negative interactions with potential "snowball" effect, can be decoupled via the deployment of renewable power generation, and carbon capture from fossil-fuelled technologies. However, such retrofits pose new challenges as wind and solar energy exhibit intermittent generation patterns. In addition, integrating thermal power plants with carbon capture and storage (CCS) imposes energy penalties and increases water requirements. In the present research, an optimization framework is developed which enables systematic decision-making for the retrofit of existing power and water infrastructure as well as investment in renewable and green technologies. A key aspect of the applied framework is the simultaneous optimization of design and operational decisions in the presence of uncertainties in the water demand, electricity demand, as well as wind and solar power availability. The proposed methodology is demonstrated for the case of the water-electricity nexus in China, and provides in-depth insights into regional characteristics of low carbon electricity generation, and their implications for water purification and wastewater treatment, demonstrating a roadmap towards sustainable energy and electricity.
\end{abstract}

\section{Keywords}

Water-Electricity Nexus, GHG emissions, Stochastic Mixed-integer Optimization, Wind and Solar Power.

\footnotetext{
${ }^{1}$ Corresponding Author: Room 1108, Roberts Building, Department of Electronic and Electrical Engineering, University College London, London, UK. WC1E 7JE. Email: m.sharifzadeh@ucl.ac.uk
} 
This article should be cited as: Mahdi Sharifzadeh, Raymond Khoo Teck Hien, Nilay Shah. China's roadmap to low-carbon electricity and water: Disentangling greenhouse gas (GHG) emissions from electricity-water nexus via renewable wind and solar power generation, and carbon capture and storage. Applied Energy Volume 235, 1 February 2019, Pages 31-42. https://doi.org/10.1016/j.apenergy.2018.10.087 (Link)

\section{Introduction}

Electricity and water are of paramount importance, whereby without them, human beings would not be able to prosper. Nonetheless, electricity and water consumption are intricately linked [1]. In a reignited debate during the 2013 UN General Assembly in New York on "Sustainable Development and Climate Change: Practical Solutions in the EnergyWater Nexus", it was emphasised that more inclusive attention must be paid to the inter-linkages between the energy and water sectors [2]. There are two standpoints for assessing the energy and water nexus. The first involves the use of water in power generation while the second relates the energy demand for water treatment. Nonetheless, greenhouse gas (GHG) emissions have significant socio-economic implications. For instance, Feng et al. [3] tracked the $\mathrm{CO}_{2}$ embedded in products in various Chinese provinces, and realized up to $80 \%$ of emissions related to goods consumed in highly developed coastal areas are actually produced in carbon-intensive industries that are located in less developed provinces. A similar argument holds for water-electricity nexus as the electricity produced in a region may be consumed in much remote area, with very different economic development, and even water availability. Therefore, quantification of environmental footprints associated water-electricity nexus can inform climate change policymakers. Significant efforts have been devoted to understanding the water-energy nexus both at regional, national and international scales. Wang et al. [4] studied water-electricity nexus in China, using a multi-regional input-output analysis. Their network analysis included the four embodied elements of the water network, energy network, energyrelated water network, and water-related energy network. They applied ecological network analysis and identified the flow of embodied water from western to eastern, and from northern to southern provinces, as well as the most controlling provincial nodes, and import-export pairs. Their analysis also revealed significant disparity in terms of the fraction of energy consumed for water treatment and purification, as well as final demand consumption which was correlated to population and economic development. Energy-water nexus analysis can be conduct at a city level, and for urban areas too. Fang and Chen [5,6] applied an input-output analysis to investigate the energy-water nexus in Beijing. The agriculture and food processing sectors were identified as the major supplier of "virtual" water, and the petroleum and natural gas processing, and electricity generation were proved to be the main supplier of urban energy. Transportation and real state sectors were classified as emerging critical nodes in the energy-water nexus. Fang and Chen [7] also studied the water-carbon nexus in China. They highlighted the interconnection between water resource utilization and $\mathrm{CO}_{2}$ emissions. Their multi-regional input-output methodology allows identifying major provinces for critical forward and backward embodied water and carbon export and import. They observed that rapidly developing provinces transfer water stress and emission burden to other regions. Sun et al. [8] highlighted the water stress in the Chinese power sector, due to excessive use of fossil fuels, especially coal. In their electricity-water nexus analysis, they identified the Beijing-Tianjin-Hebei region as one of the most water-stressed areas. They recommended a combination of advanced power generation technologies and renewable power generation to alleviate the situation. Lv et al. [9] applied interval-fuzzy chance-constrained programming to address the uncertainties in the water-energy nexus. They demonstrated their methodology for the case of the Hebei province, which heavily relies on fossil fuels for energy conversion. They highlighted the importance of water availability and uncertainty. They showed that for water-scarce scenarios, it is necessary to save water at the price of importing energy, demonstrating the tangled relationship between water and energy. Feng et al. [10] study the environmental implication of water-electricity nexus 
This article should be cited as: Mahdi Sharifzadeh, Raymond Khoo Teck Hien, Nilay Shah. China's roadmap to low-carbon electricity and water: Disentangling greenhouse gas (GHG) emissions from electricity-water nexus via renewable wind and solar power generation, and carbon capture and storage. Applied Energy Volume 235, 1 February 2019, Pages 31-42. https://doi.org/10.1016/j.apenergy.2018.10.087 (Link)

in China. Using life cycle analysis (LCA), and input-output analysis, they quantified carbon and water footprints of eight power generation technologies. They proposed that renewable power generation from wind can reduce water reliance and GHG emissions, simultaneously. Tsolas et al. [11] applied a graph-based formulation which allows graphical selection of water-energy nexus strategies. Using graph theory, they demonstrated that the optimal nexus configuration with minimum energy and water generation has no redundant flows and cycles in the network configuration. The optimal network configuration has minimum resource usage too. Nevertheless, the availability of consistent and integrated sets of data is of vital importance for electricity-water nexus analysis. Ideally, such data should be widely accessible, exhaustive and with reasonable temporal and spatial resolution. Larsen et al [12] studied the water and electricity generation nexus in the European countries. They highlighted uncertainties associated with regional data, and technological characteristics. They quantified an ensemble of median/min/max as an indicator of water use in European countries during 1980-2015. A comparative review of energy intensity and environmental impact of water supply and distribution was recently presented by Lee et al. [13]. Their quantitative survey included risk indicators regarding water quality (return flow ratio) and quantity (baseline water stress). One of their important observations was that areas with high water risk feature a higher degree of energy intensity and GHG emissions. The key observation of all these studies is the complexity of the water-electricity nexus problem, as well as its great socioeconomic and environmental impacts. These are discussed further in the following before proposing the research methodology.

In the following, the water-electricity nexus and its environmental implications are discussed in more detail. The present research aims at providing a systematic methodology to quantify the economic and environmental performance of water and electricity networks, and to address the interactions between them. In the following, the economic and environmental implication of each technology is discussed in detail, and the interactions between the water and electricity nexus, as well as their greenhouse gas footprints, are illustrated by reference to various geographical observations. These discussions illustrate the problem characteristics and provide the background to explore the analysis methods and solution algorithms that have been proposed by other researchers, to address the problem in whole or in part. Considering the research gap for a systematic methodology to address the electricity-water nexus, and the need to establish the trade-off between economic and environmental objectives, multi-objective programming is proposed in the Methodology section to address the problem. Here, the description of the model is provided. However, the details of the mathematical program are moved to the online Supplementary Materials for the sake of brevity. The development is based on extending a previous mathematical formulation [14] to include the model for the water network, as well as quantification of the water consumption in the power sector and power consumption in the water sector, and their environmental footprints. The mathematical formulation is solved using multi-objective optimization. The challenging case of water-electricity nexus in China was chosen to illustrate the application of the method, due to being a globally major water and energy consumer, as well as its regional imbalance of water and energy resources, and current air pollution issues. The results section is comprehensive and considers the scenario in which $30 \%$ of coal-fired power plants in the current Chinese electricity grid are replaced with solar and wind energy, as well as the equivalent scenario in which carbon capture and sequestration are applied. The paper concludes by illustrating the trade-off between economic and environmental objectives and emphasizing the key characteristics of the water-electricity nexus. 
This article should be cited as: Mahdi Sharifzadeh, Raymond Khoo Teck Hien, Nilay Shah. China's roadmap to low-carbon electricity and water: Disentangling greenhouse gas (GHG) emissions from electricity-water nexus via renewable wind and solar power generation, and carbon capture and storage. Applied Energy Volume 235, 1 February 2019, Pages 31-42. https://doi.org/10.1016/j.apenergy.2018.10.087 (Link)

\subsection{Electricity power generation: Water requirements and under stress resources}

The amount of water consumed globally and our reliance on its resources are extensively understated. Water resources are heterogeneously propagated around the world. While abundant resources of freshwater are accessible in some regions of the world, water scarcity is progressively being experienced in the rest. Globally, approximately 768 million citizens are deprived of high-quality water resources [15]. As stated by the International Energy Agency (IEA), the worldwide withdrawals of water for production of energy in 2010 were estimated to be 583 billion $\mathrm{m}^{3}$ (approximately $15 \%$ of worldwide withdrawals of water, surpassing the mean discharge of India's Ganges River annually [16]. The energy sector is the $2^{\text {nd }}$ largest water consumer after irrigation [17]. The energy sector's water footprint is projected to surge by $37-66 \%$ (subject to the oil price), in the future. The water footprint of a power generation technology refers to the volume of water consumed and polluted during the manufacturing of equipment and different stages of the generation process. A high oil price would induce a quicker swing to several renewables [18] that may or may not be more water-demanding compared to the present fossil fuels $[19,20]$. At present, the water consumed by power plants is mostly being contributed by groundwater and surface water supplies, which are also shared with the agricultural and urban demands.

On the other hand, the worldwide electricity demand escalated dramatically by $78 \%$ between 2000 and 2010 [16] which should be attributed to the growing population and improved living standards. In 2009, $90 \%$ of $380 \mathrm{TWh}$ of electricity generated annually in the UK was contributed by thermoelectric power stations, while nearly $50 \%$ of all water withdrawal in England and Wales was made up by the electricity sector [21]. The daily freshwater consumption of thermal power generation was about 914 million cubic meters ( $49 \%$ of overall consumption), whereby steam is utilised to run a turbine for electricity generation and water is consumed for steam condensation at the exhaust of the turbine and for internal temperatures regulation, preventing overheating [22,23]. The energy-related water demand competes with the municipal as well as the agricultural sectors. If drought situations escalate as projected with continuous global climate change, several rivers will hit extremely low levels during summer, imposing further stress on power generation.

The usage of energy in municipal water supplies can be segregated into dual key constituents: (1) energy demand during operation, and (2) energy usage for constructing as well as maintaining the equipment and infrastructure in the water industry. Majority of the energy reports do not consider analysis in relation to direct energy usage (i.e., energy demand during operation). This may be due to the complexity of achieving reliable data quality to validate those findings. The energy consumption related with end-use of water is usually neglected or studied independently from the water supply operations although it is an essential component of the water supply chain, and a significant energy consumer as well as GHG emitter [24].

\subsection{Electricity power generation: Environmental implications}

Power plants emissions contribute nearly $42 \%$ of the global $\mathrm{CO}_{2}$ emissions [25]. This sector is accountable for $32 \%$ of the $\mathrm{CO}_{2}$ emissions in the UK [26], and accounts for a key target in the UK's Climate Change Act 2008 in order to decrease the GHG emissions by $80 \%$ by 2050 [27]. In China, $40 \%$ of total emission is from coal-fired power generation. Considering the rising demand, the power sector is projected to remain the largest emitter of energyassociated GHGs [28]. For instance, $\mathrm{CO}_{2}$ emissions of the power industry escalated by $80 \%$ between 1990 
This article should be cited as: Mahdi Sharifzadeh, Raymond Khoo Teck Hien, Nilay Shah. China's roadmap to low-carbon electricity and water: Disentangling greenhouse gas (GHG) emissions from electricity-water nexus via renewable wind and solar power generation, and carbon capture and storage. Applied Energy Volume 235, 1 February 2019, Pages 31-42. https://doi.org/10.1016/j.apenergy.2018.10.087 (Link)

(introduction of the Kyoto protocol) and 2011 [25]. The quality of air continues to be a crucial issue both at the regional and national levels.

An on-going development, carbon capture and sequestration (CCS), can potentially mitigate GHG emissions from power stations at the expense of larger water requirements [29-32]. The competition for water resources can lead to further challenges in water supply, especially in arid regions. For instance, the consumption of water at new pulverised coal-fired power stations will be approximately $90 \%$ larger with the inclusion of amine-based capture systems [33]. Natural gas combined-cycle (NGCC) plants, that are retrofitted with amine-based capture processes, will also result in a 76\% increment in water consumption. With the implementation of a two-stage Selexol process, the consumption of water in gasification systems is expected to rise. Integrated gasification combined-cycle (IGCC) plants will need $45 \%$ more water, half of which is required for the water-intensive gasifier operations and water-gas shift (WGS) reactor [33]. The water demand associated with thermal power plants can be minimised at the expense of larger expenditure, by changing to a "dry cooling" approach or an entirely closed-loop system.

Due to these emerging complications, nuclear power has been placed back on the agenda in various countries [34]. Nuclear energy is extremely dense and a single fuel pellet of uranium has an equivalent amount of energy as $480 \mathrm{~m}^{3}$ of natural gas, 149 gallons of oil, or $807 \mathrm{~kg}$ of coal $[35,36]$. Apart from that, nuclear power does not emit $\mathrm{CO}_{2}$ but consumes a significant volume of cooling water.

Hydropower is another candidate solution for renewable power generation. However, recent studies discovered that a hydroelectric dam is a significant GHG emitter, partially counteracting the carbon sink in the mainland [37,38]. There is also a growing issue on the sustainability of water using hydropower $[39,40]$. In hydropower plants, approximately $68 \mathrm{~L}$ of water is utilised for $1 \mathrm{kWh}$ of electrical generation. Practically, this implies that for burning a single $60 \mathrm{~W}$ light bulb for $12 \mathrm{~h}, 36-73 \mathrm{~L}$ of water has to be utilized [41].

Wind energy is a renewable energy resource, whereby it utilises kinetic energy from air movement and converts it to electricity. Wind turbine grids are built either on-shore or off-shore [42]. Another renewable source of energy is solar energy which can be converted into electricity using photovoltaics or concentrated solar power plants. With respect to water and environmental footprints, wind and solar energy are highly advantageous because of their negligible direct water consumption and insignificant carbon footprint [43].

\subsection{Water and wastewater treatment: Energetic and environmental aspects}

In the life-cycle of water technologies, energy is required for abstraction (e.g. for ground or surface water pumping), purification (e.g. for desalination and treatment of wastewater), delivery (e.g. to channel water via long distributed pipelines and in municipal supply networks), operation (e.g. to boil water for industrial purposes, domestic utilisation and for agricultural sectors) and disposal (e.g. for on-site municipal and industrial wastewater) [44]. The net consumption of energy can differ considerably for every process which should be attributable to different geographical, technological and physical aspects. For example, 19\% of electricity in California's is associated with water facilities, including the provision of water, treatment of wastewater, agriculture and other applications [45]. In Arizona, annually over 500 billion gallons of water are supplied to the Central Arizona Project via a channel that extends 336 miles and rises almost 3000 feet from the Colorado River to Phoenix and Tucson. The Central Arizona 
This article should be cited as: Mahdi Sharifzadeh, Raymond Khoo Teck Hien, Nilay Shah. China's roadmap to low-carbon electricity and water: Disentangling greenhouse gas (GHG) emissions from electricity-water nexus via renewable wind and solar power generation, and carbon capture and storage. Applied Energy Volume 235, 1 February 2019, Pages 31-42. https://doi.org/10.1016/j.apenergy.2018.10.087 (Link)

Project is a primary electricity user in the US which consumes a quarter of the Navajo Generating Station's output to drive water through the mountains and deserts [46].

As a consequence of growing water demand, numerous urban water providers are applying seawater desalination technologies [47]. Unlike its counterparts, desalination is not affected by climatic variations and provides a steady supply. However, if fossil fuels are the sources of energy, it would sequentially develop a closed-loop feedback scheme by causing global warming which in turn gives rise to water stress. The seawater or brackish water desalination technology has improved considerably in the past decade. Latest improvements include an expansion in the unit volume, better design and materials, and upgraded membranes. In addition, hybrid technologies can result in cost reduction and minimal power consumption during desalination operations $[48,49]$. The energy consumption for desalination has also declined gradually from around $16 \mathrm{kWh}$ per $\mathrm{m}^{3}$ of water in 1970 to about $3 \mathrm{kWh}$ per m $\mathrm{m}^{3}$ in 2011 [50]. In scenarios where desalination could be considered cost-effective, it offers a significant water resource, in coastal regions. Worldwide, approximately 17,000 desalination plants are in operation in over 120 countries, supplying nearly 23 million $\mathrm{m}^{3}$ of water [51]. A major attribute is that desalination and transportation over long distance are one of the largest energy consumers in the water industry.

Wastewater treatment plants (WWTP) illustrate another classical example of the energy-water relationship in that energy is utilised for eliminating pollutants and minimising the wastewater footprint in the environmental surroundings. In spite of that, GHG emissions from respiration and consumption of power in wastewater treatment plants have drawn great attention [45,52]. Schnoor [53] stated that perhaps the biggest water feature in the 21st century is to treat wastewater via membranes and reverse osmosis for the supply of potable water with a considerable consumption of energy. In the US, water and wastewater treatment comprise about 30-40\% of the energy consumption by urban amenities. This is equivalent to GHG emissions of nearly 45 million tons per year [54]. In developed nations, WWTPs consume around 3\% of the total electricity [55]. From an energy perspective, wastewater treatment and reuse can be more cost-effective compared to desalination.

\subsection{Water, electricity and greenhouse gases (GHG): The Nexus}

Water consumed for energy production is an aspect that is relatively well researched due to its significant importance $[24,56]$. However, the energy consumption aspects of the water industry are not much explored but lately, this topic alongside its environmental consequences has garnered much attention [57,58]. Essentially, acquiring additional fresh water would be easy, if there were an infinite supply of "clean energy". Saline water would then be treated via desalination process and subsequently, the treated water would be pumped and supplied to the end users. However, as energy resources are depleting, the obstacle of providing a continuous supply of water is much more important and has numerous energy consequences. In addition, energy consumption accounts for a significant amount of GHG emissions, depending on the type of utilised fuel [59]. In Australia, electricity consumed for municipal water supply is generated by coal-fired power plants. Nearly 5\% (290 million tons) of the US overall greenhouse gas emissions per year comes from the water industry [60]. 
This article should be cited as: Mahdi Sharifzadeh, Raymond Khoo Teck Hien, Nilay Shah. China's roadmap to low-carbon electricity and water: Disentangling greenhouse gas (GHG) emissions from electricity-water nexus via renewable wind and solar power generation, and carbon capture and storage. Applied Energy Volume 235, 1 February 2019, Pages 31-42. https://doi.org/10.1016/j.apenergy.2018.10.087 (Link)

\subsection{Methods for addressing the water-electricity nexus}

The fact that the water-electricity nexus is multi-dimensional and has many interactive aspects, has posed significant conceptual and computational challenge against its systematic solution. The features of interest include the close entanglement between the two networks, the heterogeneous regional disparity of water and energy resources, as the significant contrast in the economic and environmental performance of various technologies, discussed earlier. Wu and Yan [61] highlighted that the transition of existing fossil-driven energy infrastructure to new low carbon technologies has increased the interactions and coupling of energy supply chains. Antonelli et al [62] using a demonstrating example of the Italian power network, argued that intermittencies of renewable power intensified by demand uncertainty, require careful policymaking regarding the maximum share of renewable energy systems. Fernández-Blanco et al [63] emphasized the role of hydropower for the flexible operation of power networks, using a demonstrating case in Greece. DeNooyer et al. [64] applied digital spatial datasets in conjunction with engineering techniques to develop geographic information system (GIS) models that could quantify the nexus between water resources and thermoelectric power plants in Illinois, US. Abegaz et al. [65] highlighted the need for tailor-made sensing technologies in the water infrastructure.

Fewer studies have focused on the energy-water nexus of water and wastewater treatment systems in China. Chen et al. [66] developed a framework for the urban energy-water nexus to quantify the intricate interdependencies of water use and energy consumption in Beijing. Duan and Chen [67] studied the water-energy nexus in the international energy trade context, and concluded that in a Chinese scenario, the amount of water consumed for a unit of energy was relatively larger. They attributed this observation to the indirect water use. Li et al. [43] analysed the life cycle emissions of $\mathrm{CO}_{2}$ and water consumed by China's wind power and concluded that wind energy could reduce carbon and water consumption of China's coal-dominated power generation industry. However, the authors did not incorporate all the current and possible future energy operations that consume water when assessing the regional water usage with the targets of the water industry. Yu et al. [68] utilised a bottom-up modelling based approach to measure how future strategies and technological revolutions could impact the water consumption and emissions of $\mathrm{CO}_{2}$ in coalfired power plants. Nevertheless, the technological aspects and analysis of the future outlook were only applied to coal-fired power plants and its relative consumption of water.

While a thorough review of the methods applied for modelling water-electricity nexus is beyond the scope of this paper, a detailed analysis of the related macro-assessment tools is provided by Dai et al. [69]. Wang et al. [70] studied the water-electricity nexus and its implications for the water scarcity in China. They applied the so-called virtual water flow concept which refers to the water footprint of the electricity flow within the network. They quantified the water nexus using the water scarcity index and demonstrated that a large portion of the industrial water demand is supplied through the electricity transmission, which enables balancing the inequality of water resources among various regions. Qin et al. [71] studied the water-energy nexus in the context of "3 Red-Lines policies", set by the Chinese government. They concluded that the increasing energy demand will pose challenges in future and compliance with these policies requires that the water footprint of energy sector should be considered during technology selection. Fen et al. [10] highlighted that achieving China's emission reduction policies require a significant change in the fuel mix. They applied a life cycle analysis to quantify the environmental performance of eight power generation technologies. They 
This article should be cited as: Mahdi Sharifzadeh, Raymond Khoo Teck Hien, Nilay Shah. China's roadmap to low-carbon electricity and water: Disentangling greenhouse gas (GHG) emissions from electricity-water nexus via renewable wind and solar power generation, and carbon capture and storage. Applied Energy Volume 235, 1 February 2019, Pages 31-42. https://doi.org/10.1016/j.apenergy.2018.10.087 (Link)

concluded that switching to renewable power generation from wind and solar energy could mitigate GHG emissions by $79 \%$ and reduce the demand for water by $50 \%$. Data availability plays an important role in the quantification and optimization of electricity-water nexus. Jiang and Ramaswami [72] studied the water consumption of various coalfired power generation technologies at different industrial scales. They observed significant seasonality for water requirements. They also suggested that the distinction between water withdrawal and consumption becomes negligible, due to the limited amount of water return. Fang and Chen [7] highlighted the interconnection between water consumption and $\mathrm{CO}_{2}$ emissions in China. They emphasized the transition of water stress and the pressure for compliance with emission reduction targets, from the importer nodes to the exporter nodes in the supply chain. Pan et al. [73] emphasized the uneven distribution of water and coal resources and the implication that it has for the sustainability of power generation in China, especially in the northern and western regions. A similar observation was made by Zhang and Anadon [74] who applied a mixed-unit multiregional input-output (MRIO) model and life cycle impact assessment (LCIA) method to study the effects of the uneven distribution of water and fossil-fuel resources on the sustainability of energy infrastructure in China. They highlighted that arid northern areas have higher water consumption compared to water-rich southern areas.

A summary of previous studies for supply chain optimisation is presented in Table $\mathbf{1}$ which reveals that supply chain optimisation encompassing environmental impacts is a relatively new research topic. Besides, industrial-scale practical case studies are fairly limited. Table 1 also suggests that there is a need for a systematic method for synthesizing the water-electricity nexus simultaneously. Here, we propose to apply multi-objective optimization under uncertainty, in order to simultaneously consider the interactions between the water and electricity networks through their design and operational decisions and to establish the trade-off between the competing energy and environmental objectives. The research methodology is presented in the next section, and later applied to the challenging case of water-electricity nexus in China. The features of interest include the implications that renewable wind and solar power, as well as carbon capture and sequestration have for the water-electricity nexus in China.

\section{Problem statement}

As discussed in detail earlier, electricity power generation and water networks are inextricably linked. In addition, both these industries emit considerable amounts of greenhouse gases (GHG). A resolution to disentangle GHG emissions from the electricity-water nexus is to retrofit existing thermal power plants with carbon capture and storage (CCS). However, the CCS technologies would increase the water requirements, putting additional strain on the already water-scarce regions. Solar and wind power offer alternative solutions, minimising both water and environmental footprints. Nonetheless, the main challenge intrinsic to these emerging technologies is the relatively higher economic costs and their intermittent generation, requiring additional investment in energy storage. The key observation is that achieving the objectives of electricity grid decarbonisation either through carbon capture and storage, or renewable power generation from wind and solar energy, requires a simultaneous approach to the economic and environmental gains, as well as consideration of the constraints that are imposed by the availability of the resources. The present research proposes to achieve this goal through multi-objective stochastic optimization programming, where the tradeoff between the competing objectives are established and the robustness of the solution is ensured despite the presence of uncertainties. The generation of stochastic optimization scenarios was based on clustering analysis of historical data 
This article should be cited as: Mahdi Sharifzadeh, Raymond Khoo Teck Hien, Nilay Shah. China's roadmap to low-carbon electricity and water: Disentangling greenhouse gas (GHG) emissions from electricity-water nexus via renewable wind and solar power generation, and carbon capture and storage. Applied Energy Volume 235, 1 February 2019, Pages 31-42. https://doi.org/10.1016/j.apenergy.2018.10.087 (Link)

to enable a realistic analysis. The application of such advanced method ensures that the designed infrastructure is not only robust against worst-case scenarios, but also is optimal for the most likely scenario.

To this end, the problem statement of the present research includes identification of the optimal investment in renewable power generation and storage facilities, retiring a number of existing fossil-driven technologies or retrofitting them with CCS technologies, while satisfying the electricity demand, maximising the economic potential and minimising greenhouse gas emissions. In addition, the optimization program simultaneously identifies the optimal configuration of the water and wastewater management technologies, in order to supply the water to the power generation facilities. The optimization solution also includes the operational decisions regarding the scheduling of power generators and water treatment facilities, in the presence of uncertainties in the water demand, electricity demand, wind speed and solar irradiation.

Table 1: A list of previous works on supply chain optimisation and their major contributions.

\begin{tabular}{|c|c|c|c|c|c|c|}
\hline Author(s) & $\begin{array}{l}\text { Economic } \\
\text { Objective }\end{array}$ & $\begin{array}{l}\text { GHG } \\
\text { Minimisation }\end{array}$ & $\begin{array}{l}\text { Supply Chain } \\
\text { Network Design }\end{array}$ & $\begin{array}{l}\text { Life Cycle } \\
\text { Analysis }\end{array}$ & $\begin{array}{l}\text { Type of } \\
\text { Model }\end{array}$ & $\begin{array}{l}\text { Techniques } \\
\text { Utilisation }\end{array}$ \\
\hline Sharifzadeh et al. [14] & $\checkmark$ & & $\checkmark$ & & MILP & SP \\
\hline Bojarski et al. [75] & $\checkmark$ & & $\checkmark$ & $\checkmark$ & MILP & LCA \\
\hline Chong et al. [76] & $\checkmark$ & & $\checkmark$ & & MILP & P-Graph \\
\hline Foo et al. [77] & $\checkmark$ & $\checkmark$ & & & MILP & RO \\
\hline $\begin{array}{l}\text { Guillén-Gosálbez and } \\
\text { Grossmann [78] }\end{array}$ & $\checkmark$ & & $\checkmark$ & $\checkmark$ & MINLP & SP \\
\hline Hugo et al. [79] & $\checkmark$ & $\checkmark$ & $\checkmark$ & & MILP & POS \\
\hline Lam et al. [80] & $\checkmark$ & & $\checkmark$ & & MILP & P-Graph \\
\hline Mele et al. [81] & $\checkmark$ & & $\checkmark$ & $\checkmark$ & MILP & LCA \\
\hline Pinto-Varela et al. [82] & $\checkmark$ & & $\checkmark$ & $\checkmark$ & MILP & FP \\
\hline Pozo et al. [83] & $\checkmark$ & & $\checkmark$ & $\checkmark$ & MILP & PCA \\
\hline Shabani et al. [84] & $\checkmark$ & & $\checkmark$ & & MILP & SP \\
\hline Tan et al. [77] & $\checkmark$ & & & & MILP & P-Graph \\
\hline You et al. [85] & $\checkmark$ & $\checkmark$ & $\checkmark$ & & MILP & POS \\
\hline You and Wang [86] & $\checkmark$ & $\checkmark$ & $\checkmark$ & & MILP & POS \\
\hline Zamboni et al. [87] & $\checkmark$ & $\checkmark$ & $\checkmark$ & & MILP & POS \\
\hline Zamboni et al. [88] & $\checkmark$ & $\checkmark$ & $\checkmark$ & & MILP & POS \\
\hline
\end{tabular}

$(F P=$ Fuzzy programming, $L C A=$ Life cycle analysis, $P C A=$ principal component analysis, $P O S=$ Pareto optimal solution, $R O=$ Robust optimisation, $S P=$ Stochastic programming, $M I L P=$ Mixed-integer linear programming, MINLP= Mixed-integer nonlinear programming) 
This article should be cited as: Mahdi Sharifzadeh, Raymond Khoo Teck Hien, Nilay Shah. China's roadmap to low-carbon electricity and water: Disentangling greenhouse gas (GHG) emissions from electricity-water nexus via renewable wind and solar power generation, and carbon capture and storage. Applied Energy Volume 235, 1 February 2019, Pages 31-42. https://doi.org/10.1016/j.apenergy.2018.10.087 (Link)

\section{Methodology}

Recently, Sharifzadeh, et al. [14] presented a mathematical formulation for optimal design and operation of power generation networks. That mathematical formulation was extended in the present study to include the models of the water and wastewater treatment network. In addition to the economic costs of power generation and water treatment, the environmental impacts in terms of greenhouse gas (GHG) emissions from the power and water networks were included in a multi-objective optimization program. The power network model includes constraints concerning the electricity balance around various nodes and the power losses in the transmission network, power generation from natural gas, power generation from coal, nuclear power generation, power generation from wind energy, power generation from solar energy, and electricity storage. The water network model includes constraints concerning water supply balance, wastewater treatment, membrane desalination plants, thermal desalination plants and water purification plants (from rivers). Most of all, the model includes constraints which establish the links between the power generation and water technologies, in terms of the water needed for power generation and the electricity needed for water treatment. The optimization framework includes realistic stochastic scenarios. The aim was to illustrate the implications of uncertainties in electricity demand, solar and wind power generation, as well as water demand. The optimization variables include the decisions regarding retiring the existing facilities as well as investing in new renewable power and water technologies. In addition, in some scenarios, the optimization model included the option of integrating coal-fired power plants with carbon capture and sequestration. The details of the mathematical formulation and applied data are presented in the online Supplementary Materials (SM).

\section{Case Study Descriptions}

In order to demonstrate the research methodology, it was applied to the case of retrofitting the existing electrical transmission grids in China. For the sake of brevity, the case study is reported in the online Supplementary Materials (SM). The details include the specifications of the existing infrastructure such as the transmission lines, existing natural gas power plants, coal-fired power plants, nuclear power stations, installed wind power generation capacities, solar farms and pumped storage facilities. The SM also reports the parameters of the models applied for economic and environmental studies. The aim is to illustrate the problem formulation, and ensure the reproducibility of the results. The optimization program was solved using CPLEX v12.0 in GAMS version 24.7.1.

\section{Results and discussions}

In this section, the results of the optimisation programming are presented and discussed. In the developed stochastic optimization program, the seasonal variations in wind speed, solar irradiation, electricity demand as well as water demand were included in the program. Not only does the retrofitted grid remain operational under extreme negative variations, but it also takes advantage of their positive realizations, in terms of economic profitability and environmental protection.

Furthermore, optimization was conducted with respect to both economic objectives and environmental objectives. The features of interest include the geographical implications of the water-electricity nexus, the role of renewable power technologies and carbon capture and storage (CCS) in disentangling the GHG emissions from the interaction between the water and electricity networks, and the decision support for informed policy-making. 
This article should be cited as: Mahdi Sharifzadeh, Raymond Khoo Teck Hien, Nilay Shah. China's roadmap to low-carbon electricity and water: Disentangling greenhouse gas (GHG) emissions from electricity-water nexus via renewable wind and solar power generation, and carbon capture and storage. Applied Energy Volume 235, 1 February 2019, Pages 31-42. https://doi.org/10.1016/j.apenergy.2018.10.087 (Link)

\subsection{Disentangling the greenhouse gases (GHGs) using renewable wind and solar energy}

In the first part of the results, only wind and solar power were considered for disentangling the greenhouse gas (GHG) emissions from the water-electricity nexus. Later in Section 5.2, carbon capture and storage is also included in the mathematical program. In all scenarios, the stochastic behaviours of wind and solar energy, as well as the demand for water were considered, to ensure a realistic assessment of the technological potentials.

\subsubsection{The implication of renewable energies for the power sector}

Figure 1(a) and Figure 1(b) display the results of the stochastic optimisation studies for power generation. In Scenario (a), only the economic performance was optimised. By comparison, in Scenario (b), the environmental performance was the objective function. The economic scenario (Figure 1(a)) suggests that a significant number of coal power plants still remain in operation compared to the environmental scenario (Figure 1(b)). A large distribution of coal power plants was also observed in the northern region of China as there are huge coal reserves in these regions, and coal power plants are favoured as being more cost-effective than other power generation technologies. The extra demand will be supplied by the wind and solar power. The wind turbines installation is preferred in the northern regions due to the stronger wind availability, while solar energy is favoured in the southern regions due to the higher solar intensity.
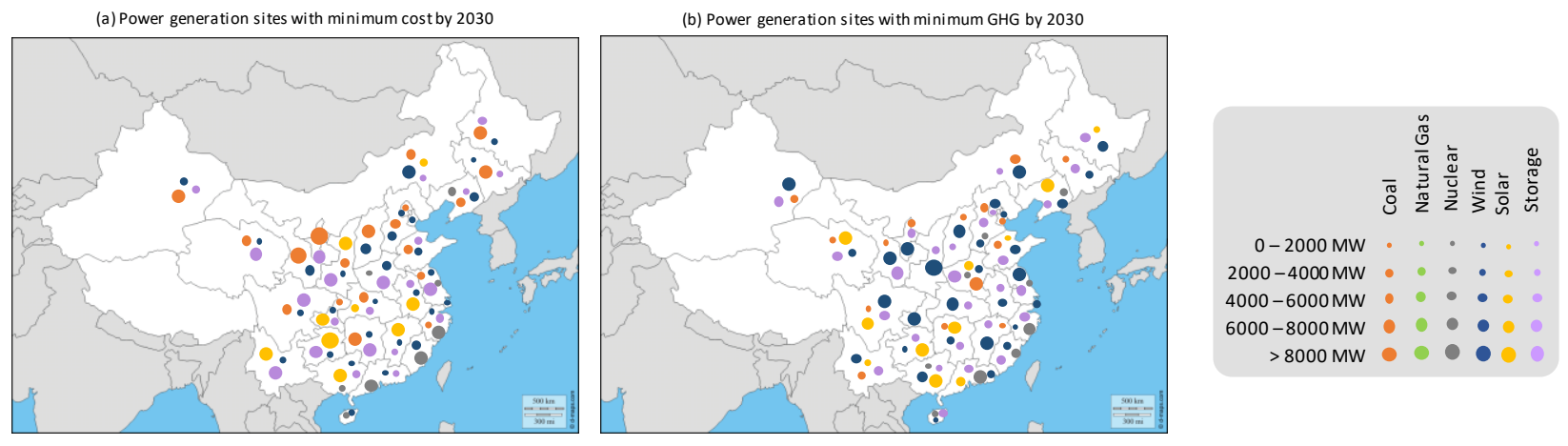

Figure 1: The geographical allocation of the existing electrical grid with new renewable power facilities.

On the other hand, for the environmental scenarios (Figure 1(b)), a greater number of renewable technologies are installed across Chinese provinces due to their lower GHG emissions compared to the coal power plants. A significant number of coal power plants are also shut down to reduce emissions. Therefore, in order to supply the total required electricity demand, a greater number of wind and solar power installations are provisioned. Large storage facilities are also installed in locations such as Hunan and Sichuan provinces to store the excess power generated by solar panels when there is low electricity demand. Again, more wind turbines are installed in the northern nodes particularly in the Gansu, Ningxia, and Shaanxi provinces due to the higher wind speed availability, while more solar panels are installed across the southern nodes such as in the Guangdong, Guangxi, and Hunan provinces as the solar intensity is higher in those locations.

In the present study, the option of investing in new natural gas power plants was included in the optimization formulation. However, the optimization program chose to not invest in this technology in the prospective economic and environmental scenarios. This observation is because power generation from natural gas is less economic compared to coal, and less environmentally friendly compared to wind and solar power. Therefore, this technology 
This article should be cited as: Mahdi Sharifzadeh, Raymond Khoo Teck Hien, Nilay Shah. China's roadmap to low-carbon electricity and water: Disentangling greenhouse gas (GHG) emissions from electricity-water nexus via renewable wind and solar power generation, and carbon capture and storage. Applied Energy Volume 235, 1 February 2019, Pages 31-42. https://doi.org/10.1016/j.apenergy.2018.10.087 (Link)

falls between these extreme scenarios. It is notable that as shale gas extraction becoming more and more commercial in China, the situation may change due to lowered exploration costs and abundance of this emerging resources, in certain areas.

It is also worth noting that the northern regions experience more water scarcity than the southern provinces. Installation of renewable wind turbines not only reduces GHG emissions, but also relieves the water stress in the northern regions, as wind generation does not consume significant volumes of water. Large capacities of nuclear power plants are also constructed near the coastal regions as nuclear power plants consume substantial quantities of water for cooling purposes, so water could be conveniently sourced from the sea.

\subsubsection{The implication of renewable energies for the water sector}

Figure 2(a) and Figure 2(b) displayed the results of the stochastic optimisation studies for water production. In Scenario (a), only the economic performance was optimised. By comparison, in Scenario (b), the environmental performance was the objective function. In the economic scenarios (Figure 2(a)), a large number of wastewater treatment plants are installed compared to the environmental scenario (Figure 2(b)). For the environmental performance (Figure 2(b)), more water purification plants are installed, rather than wastewater treatment plants, which should be attributed to the significantly larger GHG emissions associated with wastewater treatment plants (2.34 vs. $1.70 \mathrm{~kg} \mathrm{CO}_{2} / \mathrm{m}^{3}$ ). In addition, Figure 3(a) presents the number of new water production installation required to supply the water demand by 2030 while Figure 3(b) presents the corresponding capacities of the water production facilities. It can be noticed that several membrane desalination plants have been installed, where a greater number of membrane desalination facilities are designed for the minimum cost objective, compared to the minimum GHG objective. This is not surprising as the desalination process releases more GHG emissions than a water purification process, hence, resulting in a smaller number of membrane desalination plants in that scenario. It is also worth mentioning that the membrane desalination plants can only be installed in certain locations with close proximity to the ocean. Hence, from Figure 2, it can be observed that membrane desalination plants are installed in locations such as Fujian, Jiangsu and Zhejiang provinces where seawater can be conveniently extracted for conversion into the desalinated water.
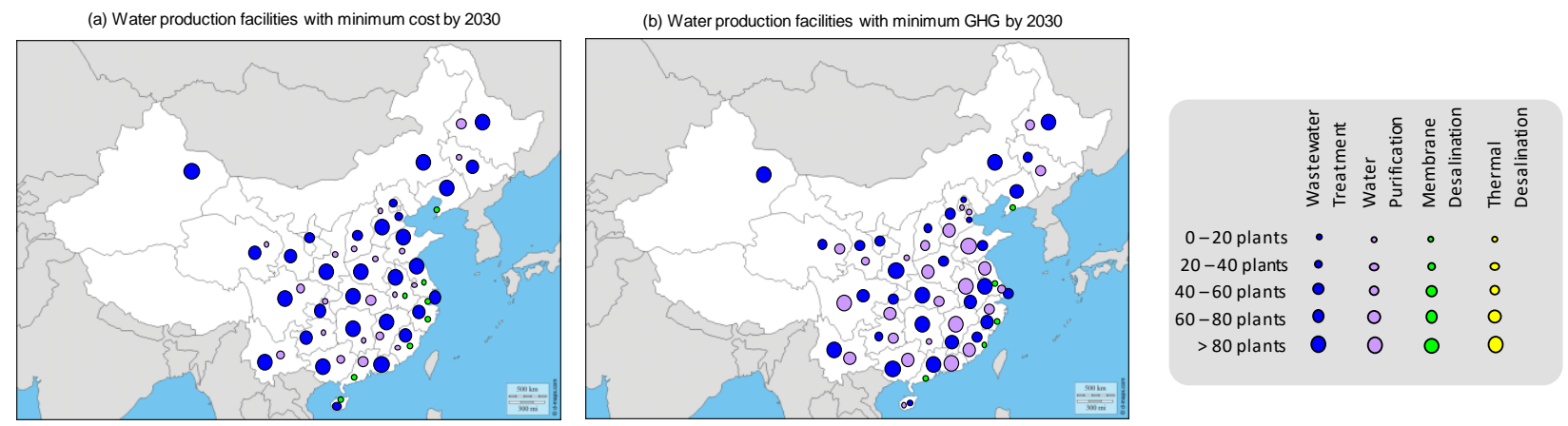

Figure 2: The geographical distribution of water production facilities across China's provinces. 


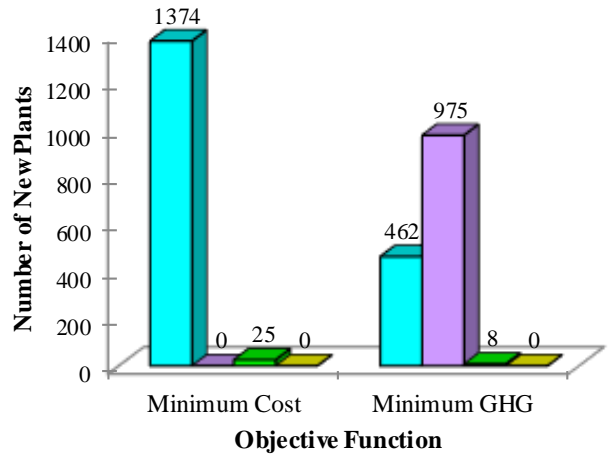

(a)

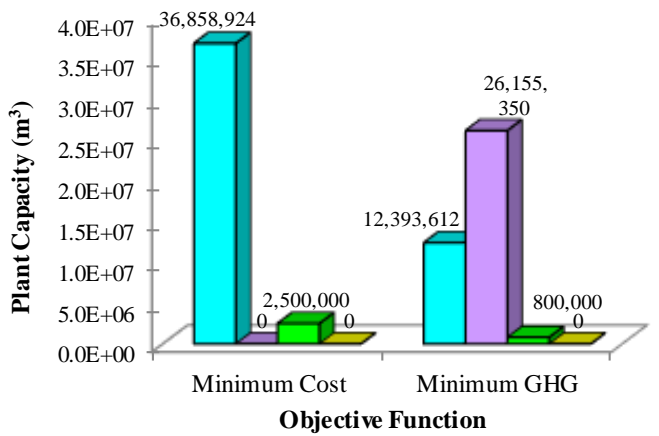

(b)

Figure 3: (a) The number of new water production plants in China by 2030; (b) The capacity of new water production facilities

in China by 2030

Figures 4-7 display the operational scheduling for the 4-seasonal stochastic scenarios. Figure 4 and Figure 5 present the seasonal variations for the power generation with economic objective and environmental objective, respectively. More electricity is being supplied by the coal power plants for the minimum cost objective (Figure 4), while more renewable energy, particularly wind power, is in operation for the minimum GHG objective (Figure 5). In addition, the energy storage deployment varies across the 4 seasons. In the summer and spring seasons, the high availability of solar allows the excess electrical power to be stored from noon till evening. During winter and autumn, this stored energy will be supplied to the electrical grid for consumption.

Figure 6 and Figure 7 depict the seasonal variations of the water production for the economic and environmental objectives, respectively. As represented in both figures, a larger volume of water is consumed during the summer and spring seasons. Wastewater treatment plants are preferred as the choice of water supply for the minimum cost scenario (Figure 6), while more water purification plants are in operation for the cleaner environmental scenario (Figure 7). Moreover, less water is consumed in the winter and autumn seasons due to the lower demands. This is directly related to the low electricity demand during winter and autumn too. Peak water demands are also observed from 9 a.m. till 7 p.m. for all the 4 seasons. 
This article should be cited as: Mahdi Sharifzadeh, Raymond Khoo Teck Hien, Nilay Shah. China's roadmap to low-carbon electricity and water: Disentangling greenhouse gas (GHG) emissions from electricity-water nexus via renewable wind and solar power generation, and carbon capture and storage. Applied Energy Volume 235, 1 February 2019, Pages 31-42. https://doi.org/10.1016/j.apenergy.2018.10.087 (Link)
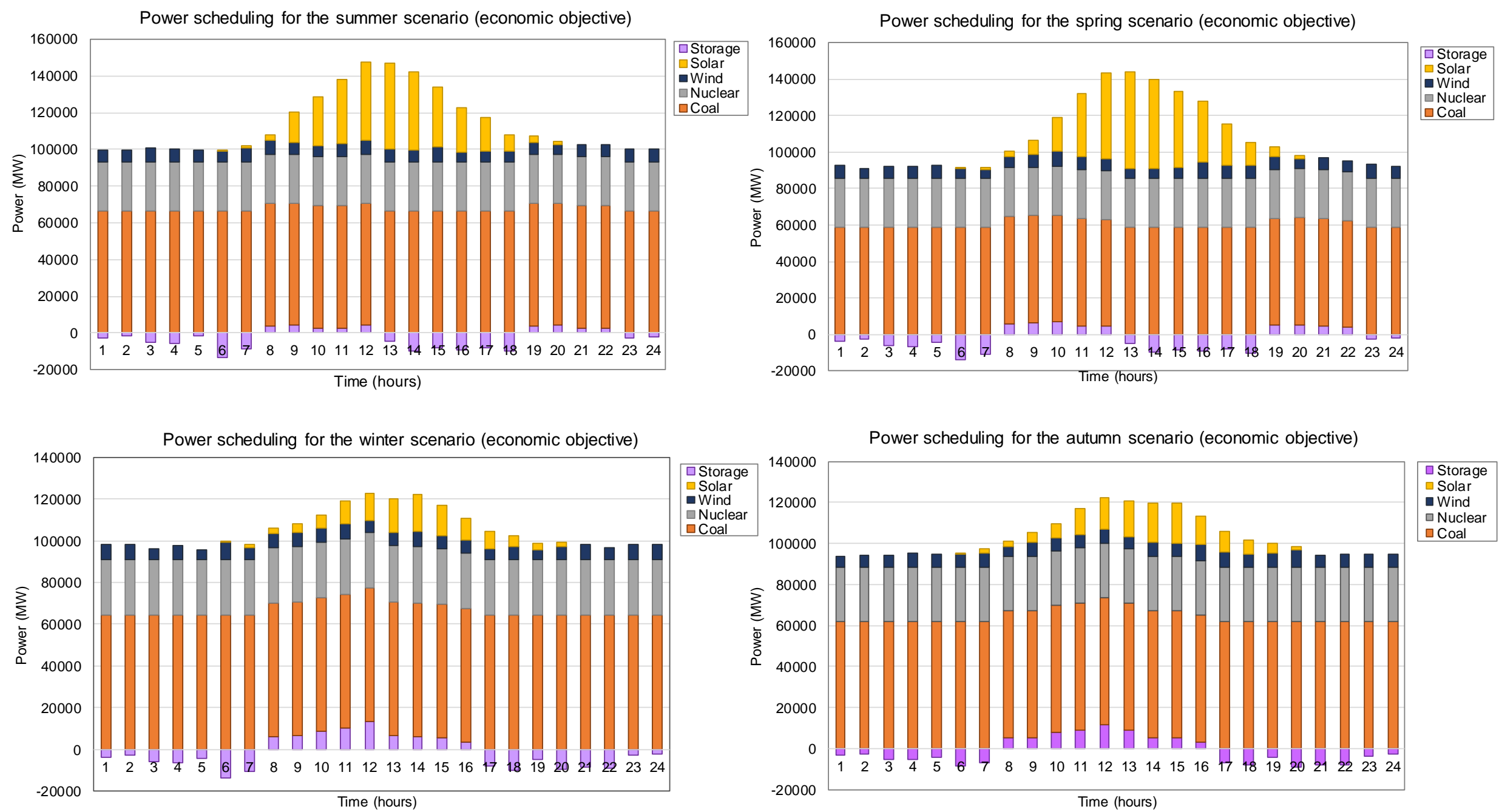

Figure 4: Operational scheduling of the stochastic scenarios (economic objective) with variation in electricity demand, wind speed, and solar irradiation. 
This article should be cited as: Mahdi Sharifzadeh, Raymond Khoo Teck Hien, Nilay Shah. China's roadmap to low-carbon electricity and water: Disentangling greenhouse gas (GHG) emissions from electricity-water nexus via renewable wind and solar power generation, and carbon capture and storage. Applied Energy Volume 235, 1 February 2019, Pages 31-42. https://doi.org/10.1016/j.apenergy.2018.10.087 (Link)

Power scheduling for the summer scenarios (environmental objective)

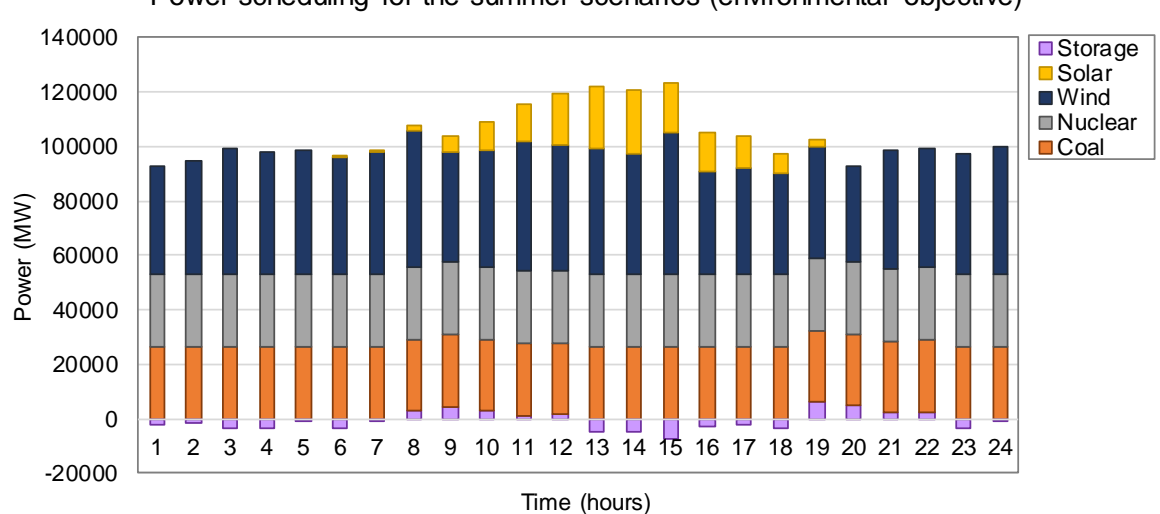

Power scheduling for the winter scenarios (environmental objective)

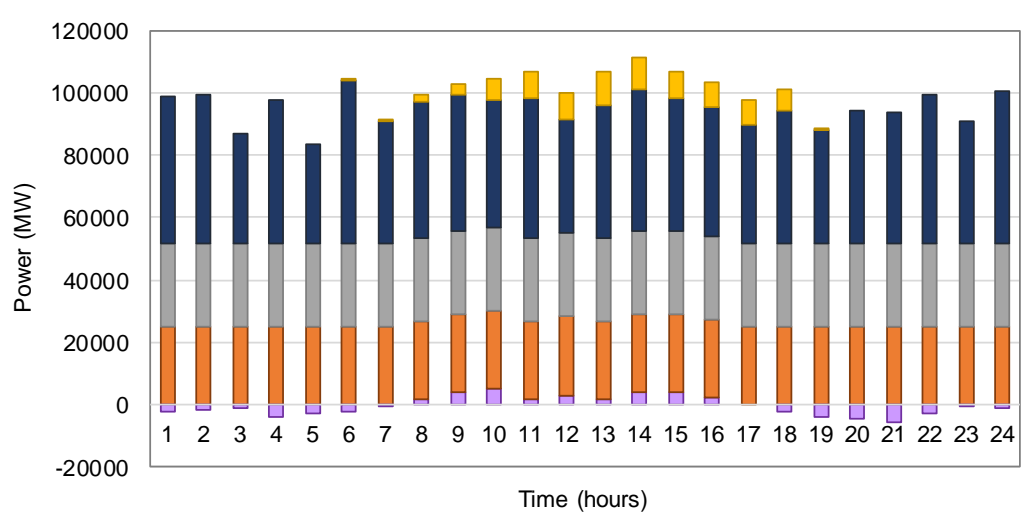

Power scheduling for the spring scenarios (environmental objective)

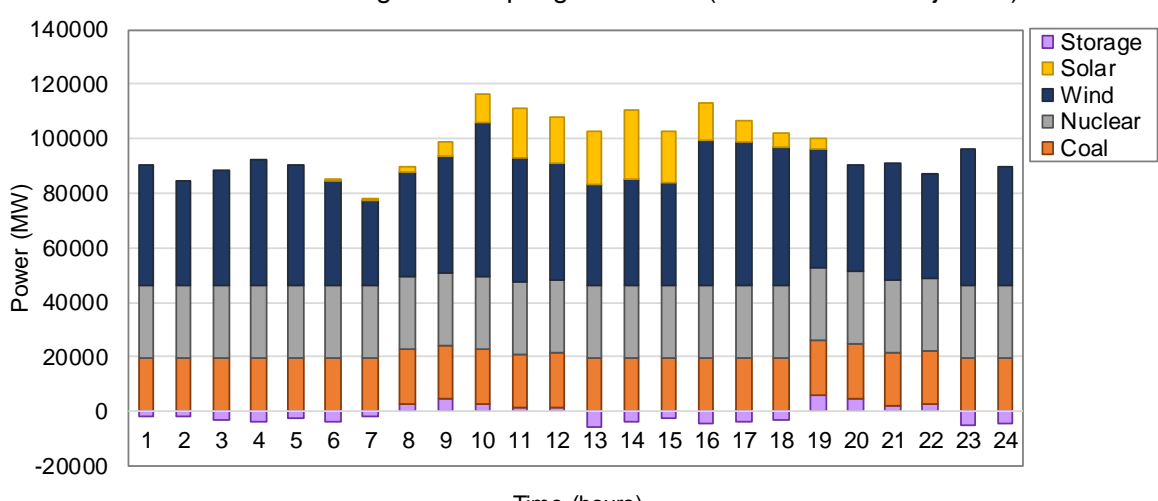

Time (hours)

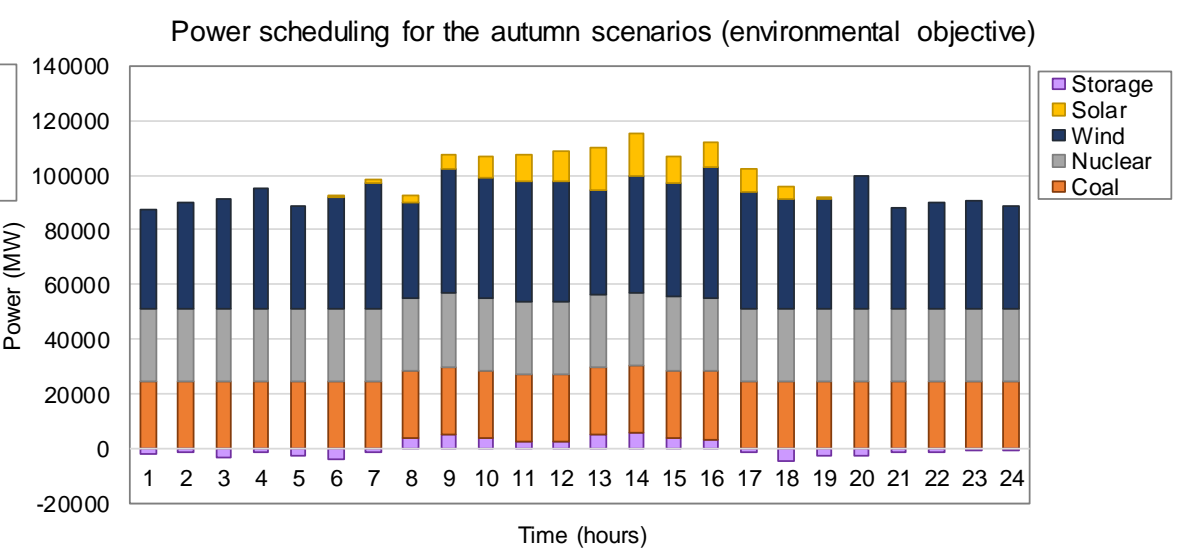

Figure 5: Operational scheduling of the stochastic scenarios (environmental objective) with variation in electricity demand, wind speed, and solar irradiation. 
This article should be cited as: Mahdi Sharifzadeh, Raymond Khoo Teck Hien, Nilay Shah. China's roadmap to low-carbon electricity and water: Disentangling greenhouse gas (GHG) emissions from electricity-water nexus via renewable wind and solar power generation, and carbon capture and storage. Applied Energy Volume 235, 1 February 2019, Pages 31-42. https://doi.org/10.1016/j.apenergy.2018.10.087 (Link)

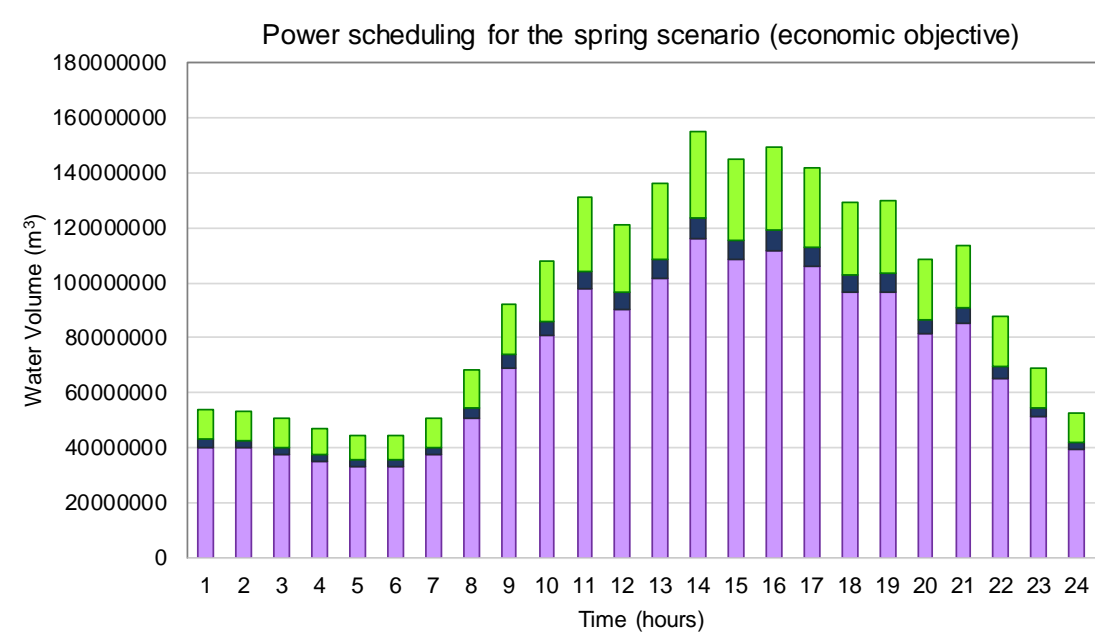

口Desalination
$\square$ Purification
$\square W W T P$
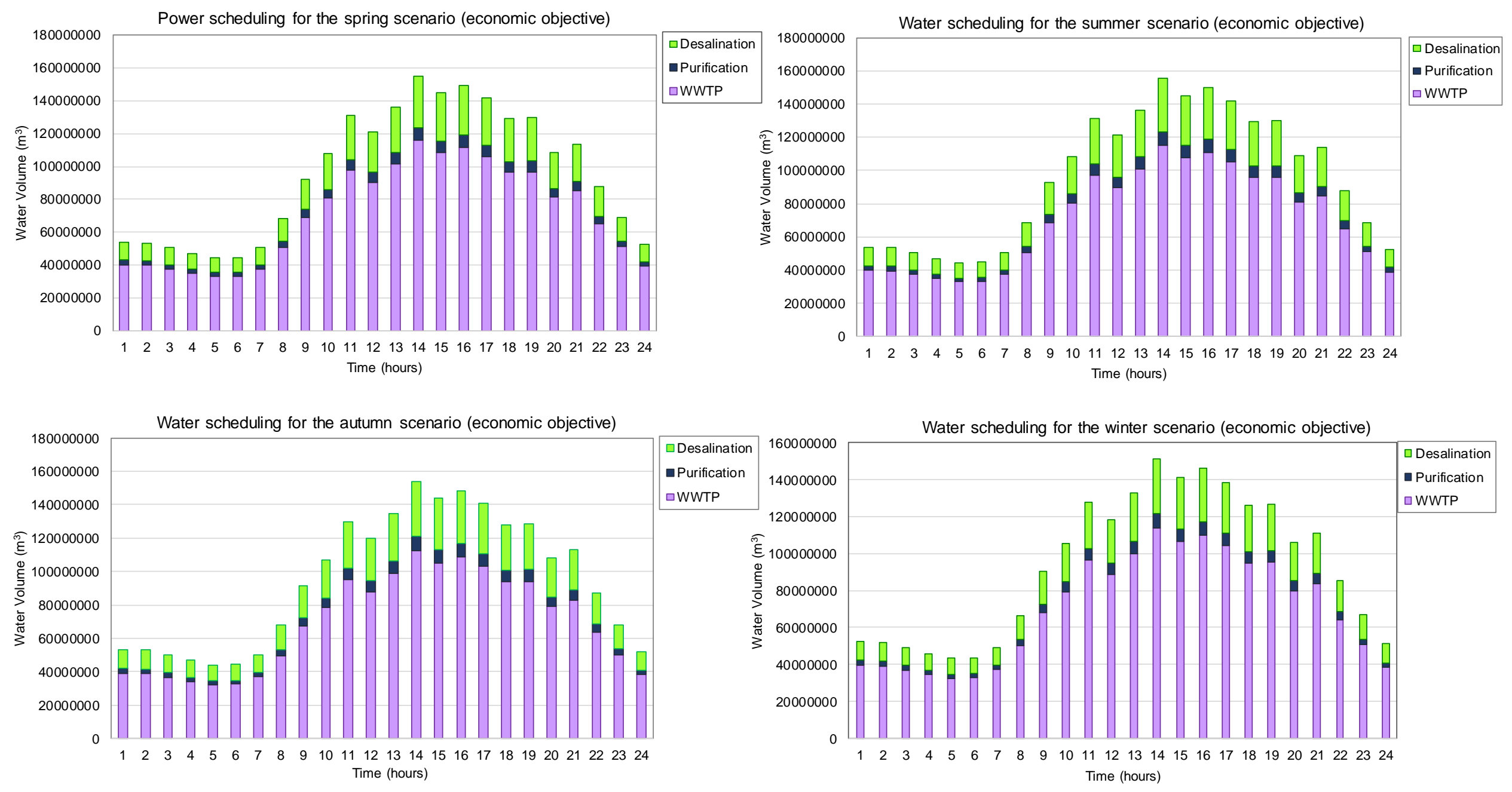

Figure 6: Operational scheduling of the stochastic scenarios (economic objective) with variation in water demand. 
This article should be cited as: Mahdi Sharifzadeh, Raymond Khoo Teck Hien, Nilay Shah. China's roadmap to low-carbon electricity and water: Disentangling greenhouse gas (GHG) emissions from electricity-water nexus via renewable wind and solar power generation, and carbon capture and storage. Applied Energy Volume 235, 1 February 2019, Pages 31-42. https://doi.org/10.1016/j.apenergy.2018.10.087 (Link)

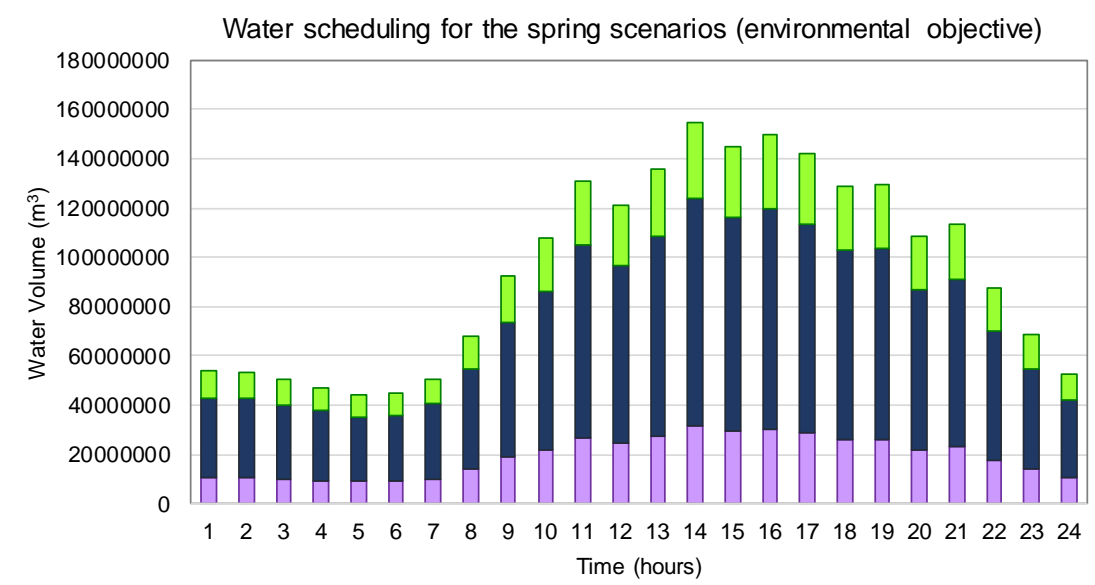

Water scheduling for the winter scenarios (environmental objective)

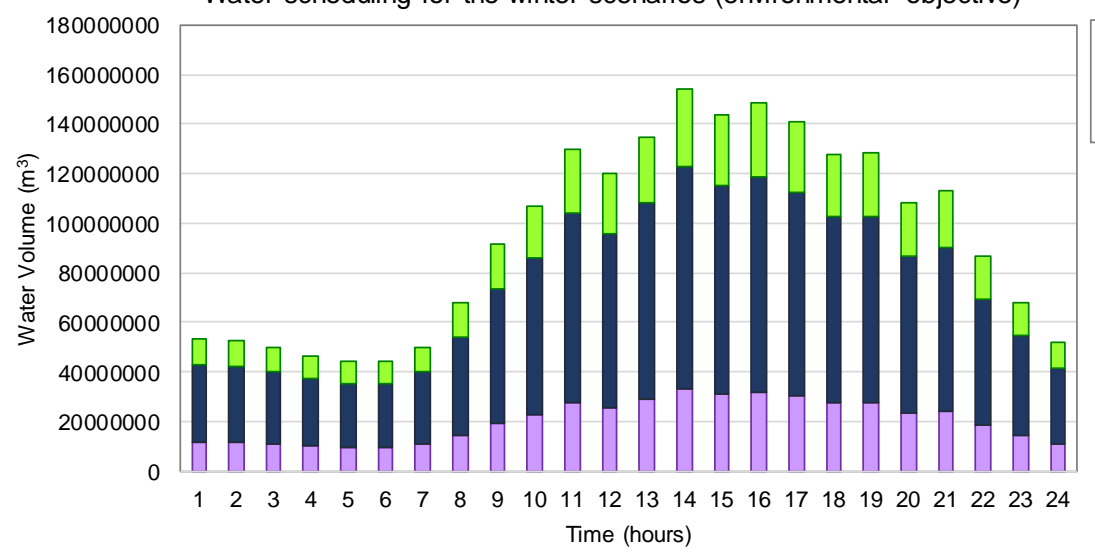

Water scheduling for the winter scenarios (environmental objective)

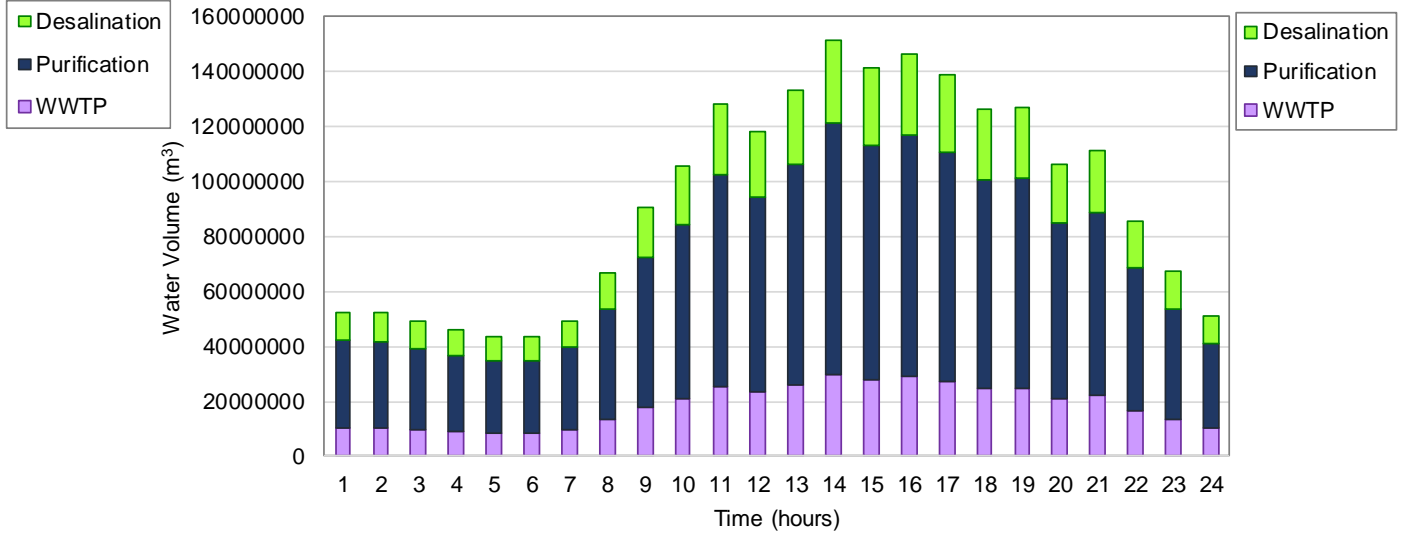

\begin{tabular}{l}
\hline Desalination \\
- Purification \\
$\square$ WWTP \\
\hline
\end{tabular}

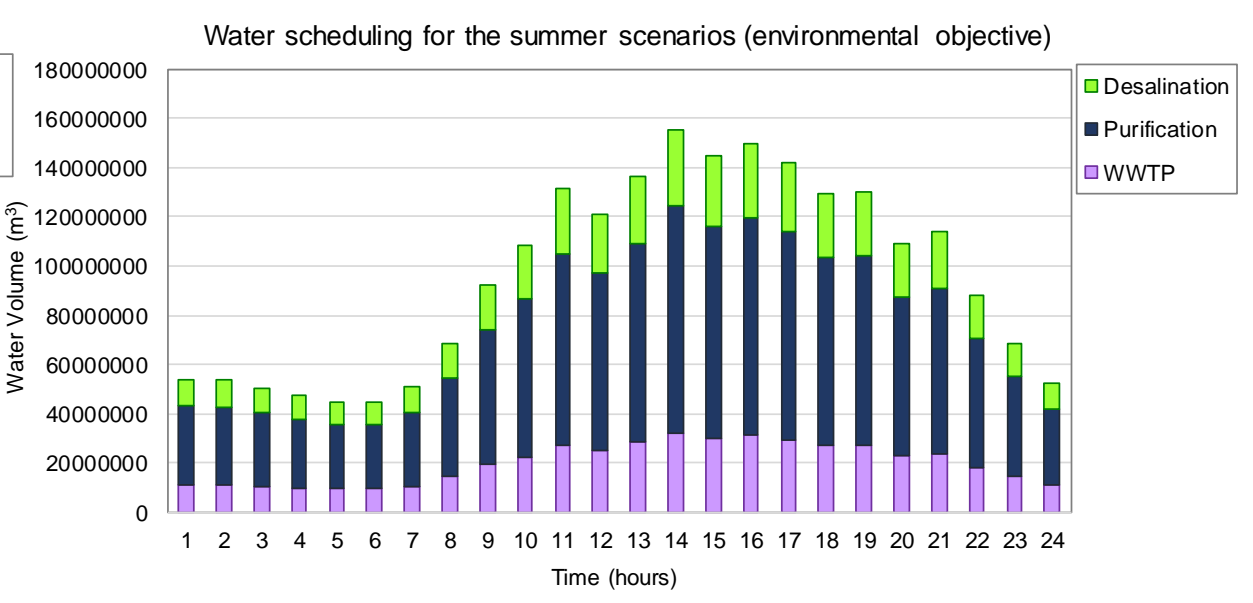

Figure 7: Operational scheduling of the stochastic scenarios (environmental objective) with variation in water demand. 
This article should be cited as: Mahdi Sharifzadeh, Raymond Khoo Teck Hien, Nilay Shah. China's roadmap to low-carbon electricity and water: Disentangling greenhouse gas (GHG) emissions from electricity-water nexus via renewable wind and solar power generation, and carbon capture and storage. Applied Energy

Volume 235, 1 February 2019, Pages 31-42. https://doi.org/10.1016/j.apenergy.2018.10.087 (Link)

5.2. Disentangling the greenhouse gases (GHGs) with an additional option for carbon capture and storage (CCS)

As mentioned earlier, China is committed to reducing the GHG emissions from coal-fired power plants by $30 \%$ $[10,89]$. Integration of carbon capture and storage (CCS) technology with the existing coal power plants is an alternative method to mitigate the associated greenhouse gas emissions. This would allow China to save the extra cost and complex efforts in decommissioning the coal power plants. Therefore, this section studies the implications of CCS for the water-electricity-GHG nexus.

\subsubsection{The implication of the CCS integration for the power sector}

In Figure 8, the locations of existing power generation facilities retrofitted with carbon capture technology are presented. In Scenario (a), only the economic performance was optimised. By comparison, in Scenario (b), only the environmental performance was the objective function. It was observed that a larger number of the coal power plants are integrated with the CCS technology in Scenario (b) compared to Scenario (a), in order to mitigate the greenhouse gas emissions. However, there are economic penalties associated with the CCS integration which include significantly larger water consumptions, resulting in higher operational costs. Hence, in Scenario (a), i.e., the minimum cost scenario, only a few coal power plants are retrofitted with CCS.

Furthermore, it was observed that a large number of CCS plants are installed in the southern provinces (see Scenario (b) in Figure 8). This observation is due to the higher availability of water in the southern regions required for CCS.
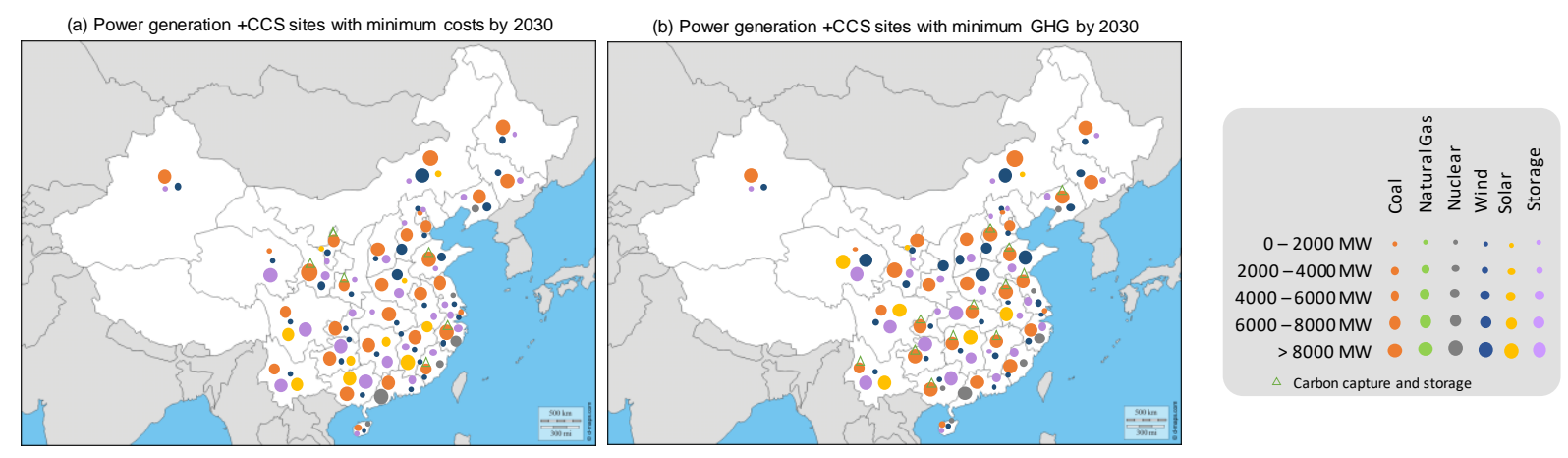

Figure 8: The geographical allocation of the existing electrical grid retrofitted with carbon capture (CC).

\subsubsection{The implication of the CCS integration for the water sector}

Figure 9 shows the total number of new water production facilities to be installed in China by 2030 to accommodate the increase in water demand. This includes the uncertainties in water demand too. It can be seen that wastewater treatment plants and membrane desalination plants are preferred for the economic objective whilst more water purification plants are chosen for the environmental objective. 
This article should be cited as: Mahdi Sharifzadeh, Raymond Khoo Teck Hien, Nilay Shah. China's roadmap to low-carbon electricity and water: Disentangling greenhouse gas (GHG) emissions from electricity-water nexus via renewable wind and solar power generation, and carbon capture and storage. Applied Energy

Volume 235, 1 February 2019, Pages 31-42. https://doi.org/10.1016/j.apenergy.2018.10.087 (Link)

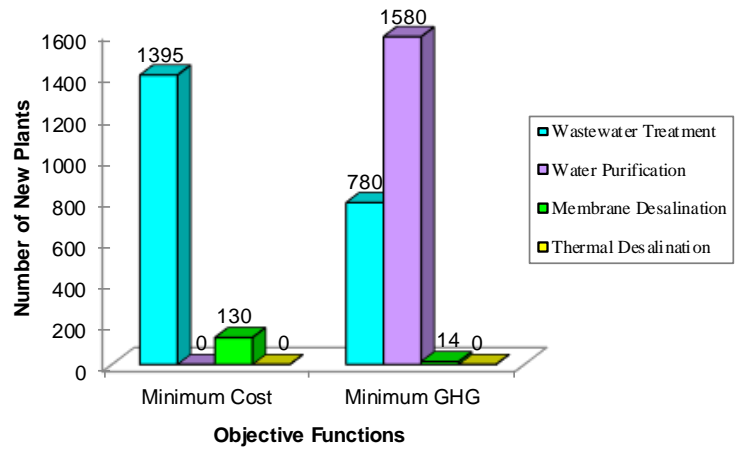

Figure 9: The number of new water production plants in China by 2030, for the scenario including CCS.

\subsection{Informed policy-making: replacing $30 \%$ of coal power plants with renewable technologies versus} CCS integration with existing coal power plants

This section compares the two case studies of (1) replacing 30\% of coal power plants with renewable wind and solar technologies, (2) retrofitting the existing coal power plants with carbon capture and sequestration (CCS), for the equivalent GHG mitigation objective. Tables 2 and 3 report the total daily cost as the summation of the total capital (investment) and operational costs, as well as the environmental objective in terms of the GHG emissions for case studies (1) and (2), respectively. The key factor that affects the optimised economic and environmental objectives is the difference between the capital costs, operational costs and the installation of new renewable technologies. The second and third row in Table 2 and Table 3 list the optimum values for the economic and environmental objective functions, respectively. A one-to-one comparison of the economic objective values in case studies (1) and (2) reveals that retiring the coal-fuel power plants and investing in renewable wind and solar power generators is a more cost-effective strategy, compared to the decarbonization of the existing coal-based grid via CCS integration. The reason should be attributed to the additional costs of CCS (in terms of capital investment and energy penalties) and its significant demand for water, which would increase the pressure on the already-stressed water resources. This conclusion is despite the minor increase in the environmental footprint which should be attributed to the indirect GHG emissions from manufacturing solar and wind power generation equipment.

Table 2: Objective functions and model statistics for the case study (1).

\begin{tabular}{lll}
\hline & Economic objective & GHG objective \\
\hline Total Daily Cost (¥/day) & $3.760 \times 10^{9}$ & $2.097 \times 10^{10}$ \\
Total GHG Emissions (kg CO 2 /day) & $405,954.61$ & $342,800.30$ \\
Number of Variables & 135,048 & 135,048 \\
Number of Constraints & 325,655 & 325,655 \\
Computational Time* & $00: 05: 31$ & $00: 32: 15$ \\
\hline
\end{tabular}

* Note that the computational time is expressed as hours:minutes:seconds 
This article should be cited as: Mahdi Sharifzadeh, Raymond Khoo Teck Hien, Nilay Shah. China's roadmap to low-carbon electricity and water: Disentangling greenhouse gas (GHG) emissions from electricity-water nexus via renewable wind and solar power generation, and carbon capture and storage. Applied Energy

Volume 235, 1 February 2019, Pages 31-42. https://doi.org/10.1016/j.apenergy.2018.10.087 (Link)

Table 3: Objective functions and model statistics for the case study (2).

\begin{tabular}{lll}
\hline & Economic objective & GHG objective \\
\hline Total Daily Cost (¥/day) & $3.975 \times 10^{9}$ & $2.051 \times 10^{10}$ \\
Total GHG Emissions (kg CO$/$ day) & $436,013.42$ & $371,068.14$ \\
Number of Variables & 135,048 & 135,048 \\
Number of Constraints & 296,855 & 296,855 \\
Computational Time* $^{*}$ & $00: 02: 04$ & $00: 05: 48$ \\
\hline
\end{tabular}

* Note that the computational time is expressed as hours:minutes:seconds

The Pareto fronts shown in Figure 10 illustrates the intense trade-offs between the economic and environmental objectives of China's water-electricity nexus, for the above-mentioned case studies. The Pareto optimal solutions are obtained using the $\varepsilon$-constraint method for multi-objective optimization programming. The shape of the Pareto front clearly indicates that in order to reduce (i.e., optimize) one of the objectives, the other objective has to increase (i.e., be sacrificed). By decreasing the total GHG emissions objective, a gradual increase in the total daily cost is observed in the first section of the Pareto curve. The details of the optimal solution suggested a different supply chain network, hence, the gradual increase in the overall cost objective. Upon decreasing the total GHG emissions further, the cost objective exhibits a linear increment before the Pareto curves approach the last section, whereby the curves flatten. Only a small increase in the total daily cost is observed in the last section as the supply chain network limitations are reached.

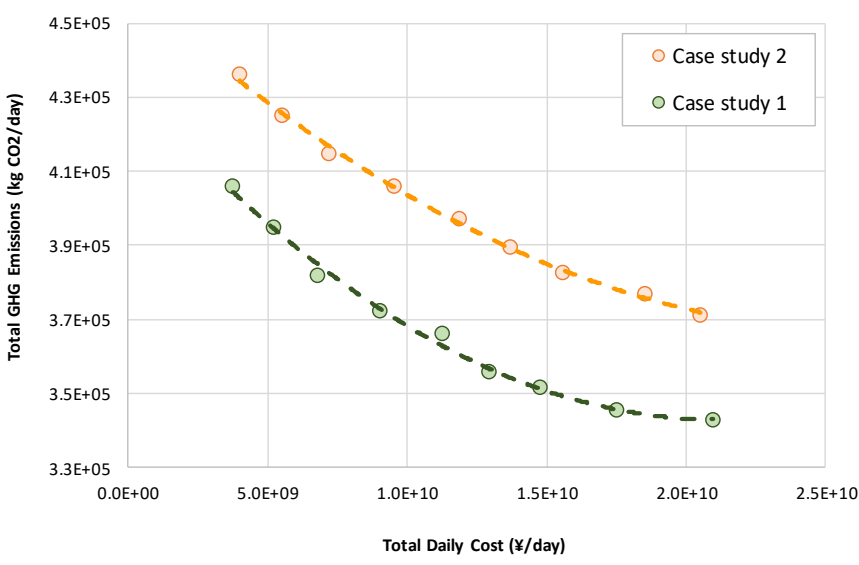

Figure 10: Pareto curves for the water-electricity nexus in China.

It should be noted that shutting down coal power plants may incur extra costs for decommissioning and a large number of coal reserves may be left unutilised which is a waste of resources since coal is cheap and abundant in China. Nonetheless, all these emerging technologies are subject to technical changes and reductions in costs. Hence, the optimal solution would be the region in the middle of the Pareto curve, in which some of the coal power plants are shut down, some of the coal power plants are retrofitted with CCS technologies, while the extra electricity demand is supplied by renewable power.

\section{Conclusions}

Globally, energy and water are regarded as a single nexus due to the strong mutual dependencies. Nonetheless, the escalating worldwide demand for energy and water has led to a significant amount of greenhouse gas emissions. Hence, there is a stringent need to establish a broader nexus - "energy-water-greenhouse gas" - where the effects of water requirements for energy conversion, energy-related utilisation of water and the associated greenhouse gas emissions are considered simultaneously. The present research addressed this gap by developing 
This article should be cited as: Mahdi Sharifzadeh, Raymond Khoo Teck Hien, Nilay Shah. China's roadmap to low-carbon electricity and water: Disentangling greenhouse gas (GHG) emissions from electricity-water nexus via renewable wind and solar power generation, and carbon capture and storage. Applied Energy

Volume 235, 1 February 2019, Pages 31-42. https://doi.org/10.1016/j.apenergy.2018.10.087 (Link)

a novel energy-water-greenhouse nexus framework in the context of power generation, using multi-objective optimisation under uncertainty. A mixed-integer (piece-wise) linear program (MILP) was formulated and solved using CPLEX v12.0 in GAMS version 24.7.1. The key objectives were to maximise economic potentials, while minimising the environmental impacts associated with the consumption of both electricity and water via (1) the retirement of existing polluting power generation systems, or their integration with carbon capture technologies, (2) the investment in renewable power technologies, and (3) the investment in water and wastewater treatment technologies.

China was selected as the demonstrating case study due to its major regional imbalance of energy and water resources, as well as its current polluted air condition, in the major cities. Globally, China is the largest energy and water consumer. Therefore, maintaining a sustainable energy-water nexus is crucial for China's economic and environmental sustainability. As China pledged to reduce its dependency on coal power plants and with the major boost in its renewable technologies, it is heading towards a greener nation by 2030. A holistic case study was developed for the geographical region of China, in which the overall electricity generation was constrained to be supplied by at least $40 \%$ of renewable power technologies.

While renewable technologies have the potential to decouple the negative environmental impacts of the interactions between electricity grids and water networks, the major challenge is their intermittent generation patterns and high associated uncertainties. Extra complications arise from the fact that the wind potential lies mostly in the northern regions whilst solar irradiation is high mainly in the southern and southwest parts of China. Hence, the ability to supply sufficient electrical power and water provisions to meet both the electricity and water demand across all the provinces by 2030 is extremely challenging.

In the present study, overarching stochastic scenarios, as well as a regional clustering of energy generation and water production technologies were performed for a realistic modelling of the energy-water-GHG nexus in China. Data on the variety of energy and power generation technologies are widely available but the availability of water data was limited. Hence, detailed attempts in gathering and assimilating those constraints coupled with comprehensive research of the scattered distribution of both energy and water resources in China were developed in order to achieve an accurate and robust solution. In order to address the fluctuations in electricity and water demand as well as the wind and solar variability, four seasonal stochastic scenarios were implemented. The seasonal stochastic scenarios were generated using five years of realistic and accurate data. A k-means clustering technique was utilised to generate representative scenarios for the electricity and water demand as well as the wind speed and solar irradiation. Nevertheless, a key feature of the proposed methodology is simultaneous optimization and integration between design and operational decisions, which has proved efficient in accommodating uncertainties and dealing with fluctuations and disturbances [29,32,90-93].

The results demonstrate that retrofitting the electrical grids with renewable technologies such as wind and solar is promising to abate environmental pollution in China. Despite the higher initial investment costs, these renewable power technologies do not consume a significant volume of water, hence, placing fewer burdens on the waterscarce northern regions of China. Additionally, CCS facilities become advantageous when there is a low generation of renewable resources coupled with high demand for electricity. With dwindling water supply, installing new wastewater treatment plants is more cost-effective compared to other water production facilities. For the environmental objective, employing water purification process particularly via reverse osmosis seems to be the optimal solution. Moreover, by 2030, the projected water demand in China would sum up to about 818 
This article should be cited as: Mahdi Sharifzadeh, Raymond Khoo Teck Hien, Nilay Shah. China's roadmap to low-carbon electricity and water: Disentangling greenhouse gas (GHG) emissions from electricity-water nexus via renewable wind and solar power generation, and carbon capture and storage. Applied Energy

Volume 235, 1 February 2019, Pages 31-42. https://doi.org/10.1016/j.apenergy.2018.10.087 (Link) billion $\mathrm{m}^{3}$ per annum which will dramatically exceed the current water supply of 606 billion $\mathrm{m}^{3}$ nationwide. Hence,

China is seeking to engineer its way out of water shortages by installing new membrane desalination plants, which are mostly located near the coastal provinces for easy adaptability and accessibility of seawater. On the other hand, it was noticed that despite the longer computational time and effort, stochastic scenarios provide a realistic solution for the electricity grid and water network. Storage facilities, particularly hydropower, are vital to dampen out the renewable power variability triggered by the daily variations in wind and solar irradiation as well as to store the excess power generated when the demand is low. The Pareto curves also dictate clear trade-off relationships for the economic and environmental objectives of the energy-water-GHG nexus. The proposed model will then allow us to select the best decisions for a sustainable design and operation of supply chain network.

In addition, mitigation of GHG emissions using carbon capture and storage (CCS) could be an alternative to curb the major air pollution issues in China. This would also allow China to continue its current operation of coal power plants without the need to shut them down. However, there are several economic penalties associated with the installation of CCS technology which includes its higher capital expenditure and overall operational costs (additional water consumption and power loss). In this respect, renewable energy seems to be more favoured due to its almost zero carbon emissions but the drawback of renewables is their intermittency issues which led to the additional utilisation of more coal power plants during the low generation and peak demand periods. Hence, the key message of this work is that flexibility is the key enabler for high penetration of renewable energies or CCS technology into conventional electricity grids. When the wind speed and solar irradiation are high, wind and solar power can be fully utilised whilst during low generation periods, CCS technology will be favoured. Another remark is that storage facilities are vital to dampen out the renewable power variability triggered by the daily variations in wind and solar irradiation as well as to store the excess power generated when the demand is low. Finally, the Pareto curves also clearly demonstrated the trade-off relationships between the economic and environmental objectives. In order to minimise the total GHG emissions, there is the penalty of higher incurred costs. Similarly, to have a minimum cost, more GHG will be emitted to the environment. To conclude, China's roadmap for a $40 \%$ electricity generation from renewable technologies by 2030 is achievable provided that every key factor such as the total investment cost and the intermittent nature are taken into account in an integrated formwork for the electricity-water-GHG nexus.

\section{References}

[1] Gu A, Teng F, Wang Y. China energy-water nexus: Assessing the water-saving synergy effects of energy-saving policies during the eleventh Five-year Plan. Energy Convers Manag 2014;85:630-7. doi:10.1016/j.enconman.2014.04.054.

[2] Kumar P, Saroj DP. Water-energy-pollution nexus for growing cities. Urban Clim 2014. doi:10.1016/j.uclim.2014.07.004.

[3] Feng K, Davis SJ, Sun L, Li X, Guan D, Liu W, et al. Outsourcing CO2 within China. Proc Natl Acad Sci 2013. doi:10.1073/pnas.1219918110.

[4] Wang S, Liu Y, Chen B. Multiregional input-output and ecological network analyses for regional energy-water nexus within China. Appl Energy 2018. doi:10.1016/j.apenergy.2017.11.093.

[5] Fang D, Chen B. Linkage analysis for the water-energy nexus of city. Appl Energy 2017;189:770-9. doi:10.1016/j.apenergy.2016.04.020.

[6] Fang D, Chen B. Water-energy control relationship in socio-economic system. Energy Procedia, 2016. doi:10.1016/j.egypro.2016.06.149.

[7] Fang D, Chen B. Linkage analysis for water-carbon nexus in China. Appl Energy 2018;225:682-95. doi:10.1016/j.apenergy.2018.05.058.

[8] Sun L, Pan B, Gu A, Lu H, Wang W. Energy-water nexus analysis in the Beijing-Tianjin-Hebei region: Case of electricity sector. Renew Sustain Energy Rev 2018. doi:10.1016/j.rser.2018.04.111. 
This article should be cited as: Mahdi Sharifzadeh, Raymond Khoo Teck Hien, Nilay Shah. China's roadmap to low-carbon electricity and water: Disentangling greenhouse gas (GHG) emissions from electricity-water nexus via renewable wind and solar power generation, and carbon capture and storage. Applied Energy

Volume 235, 1 February 2019, Pages 31-42. https://doi.org/10.1016/j.apenergy.2018.10.087 (Link)

[9] Lv J, Li YP, Shan BG, Jin SW, Suo C. Planning energy-water nexus system under multiple uncertainties - A case study of Hebei province. Appl Energy 2018;229:389-403. doi:10.1016/J.APENERGY.2018.08.010.

[10] Feng K, Hubacek K, Siu YL, Li X. The energy and water nexus in Chinese electricity production: A hybrid life cycle analysis. vol. 39. Pergamon; 2014. doi:10.1016/j.rser.2014.07.080.

[11] Tsolas SD, Karim MN, Hasan MMF. Optimization of water-energy nexus: A network representationbased graphical approach. Appl Energy 2018;224:230-50. doi:10.1016/J.APENERGY.2018.04.094.

[12] Larsen MAD, Drews M. Water use in electricity generation for water-energy nexus analyses: The European case. Sci Total Environ 2019;651:2044-58. doi:10.1016/J.SCITOTENV.2018.10.045.

[13] Lee M, Keller AA, Chiang P-CC, Den W, Wang H, Hou C-HH, et al. Water-energy nexus for urban water systems: A comparative review on energy intensity and environmental impacts in relation to global water risks. Appl Energy 2017;205:589-601. doi:10.1016/j.apenergy.2017.08.002.

[14] Sharifzadeh M, Lubiano-Walochik H, Shah N. Integrated renewable electricity generation considering uncertainties: The UK roadmap to 50\% power generation from wind and solar energies. Renew Sustain Energy Rev 2017;72:385-98. doi:10.1016/j.rser.2017.01.069.

[15] WWAP- United Nations World Water Assessment Programme. The United Nations World Water Development Report 2014: Water and Energy. Paris: 2014.

[16] International Energy Agency. World Energy Outlook 2012. OECD Publishing; 2012. doi:10.1787/weo2012-en.

[17] Hightower M, Pierce SA. The energy challenge. Nature 2008;452:285-6.

[18] Mirchi A, Hadian S, Madani K, Rouhani OM, Rouhani AM. World energy balance outlook and OPEC production capacity: Implications for global oil security. Energies 2012. doi:10.3390/en5082626.

[19] Gerbens-Leenes PW, Hoekstra AY, van der Meer T. The water footprint of energy from biomass: A quantitative assessment and consequences of an increasing share of bio-energy in energy supply. Ecol Econ 2009. doi:10.1016/j.ecolecon.2008.07.013.

[20] Hadian S, Madani K. The Water Demand of Energy: Implications for Sustainable Energy Policy Development. Sustainability 2013;5:4674-87. doi:10.3390/su5114674.

[21] Department for Environment Food \& Rural Affairs. Water quality and abstraction statistics: ENV15 Water abstraction tables. 2017.

[22] Barber NL. Summary of estimated water use in the United States in 2005: U.S. Geological Survey Fact Sheet 2009. 2009.

[23] Sovacool BK, Sovacool KE. Identifying future electricity-water tradeoffs in the United States. Energy Policy 2009;37:2763-73. doi:10.1016/j.enpol.2009.03.012.

[24] Rothausen SGSA, Conway D. Greenhouse-gas emissions from energy use in the water sector. Nat Clim Chang 2011. doi:10.1038/NCLIMATE1147.

[25] IEA. CO2 Emissions From Fuel Combustion. 2015. doi:10.1787/co2-table-2011-1-en.

[26] DECC. DIGEST OF UNITED KINGDOM ENERGY STATISTICS 2015. 2015. doi:10.1016/B978-012-088759-0.00001-8.

[27] Byers EA., Hall JW., Amezaga JM. Electricity generation and cooling water use: UK pathways to 2050. Glob Environ Chang 2014. doi:10.1016/j.gloenvcha.2014.01.005.

[28] International Energy Agency (IEA). Climate \& electricity annual - Data \& analysis. Paris: 2011.

[29] Sharifzadeh M, Shah N. Comparative studies of $\mathrm{CO} 2$ capture solvents for gas-fired power plants: Integrated modelling and pilot plant assessments. Int J Greenh Gas Control 2015;43. doi:10.1016/j.ijggc.2015.10.009.

[30] Sharifzadeh M, Shah N. Carbon capture from natural gas combined cycle power plants: Solvent performance comparison at an industrial scale. AIChE J 2016;62:166-79. doi:10.1002/aic.15072.

[31] Sharifzadeh M, Bumb P, Shah N. Carbon capture from pulverized coal power plant (PCPP): Solvent performance comparison at an industrial scale. Appl Energy 2016;163:423-35. doi:http://dx.doi.org/10.1016/j.apenergy.2015.11.017.

[32] Sharifzadeh M, Shah N. MEA-based CO2 capture integrated with natural gas combined cycle or pulverized coal power plants: Operability and controllability through integrated design and control. J Clean Prod 2019;207:271-83. doi:10.1016/J.JCLEPRO.2018.09.115.

[33] Gerdes K, Nichols C. Water Requirements for Existing and Emerging Thermoelectric Plant Technologies. 2009.

[34] Karakosta C, Pappas C, Marinakis V, Psarras J. Renewable energy and nuclear power towards sustainable development: Characteristics and prospects. Renew Sustain Energy Rev 2013. doi:10.1016/j.rser.2013.01.035.

[35] World Nuclear Association (WNA). Uranium, Electricity and Climate Change 2012. http://www.worldnuclear.org/information-library/energy-and-the-environment/uranium,-electricity-and-climate- 
This article should be cited as: Mahdi Sharifzadeh, Raymond Khoo Teck Hien, Nilay Shah. China's roadmap to low-carbon electricity and water: Disentangling greenhouse gas (GHG) emissions from electricity-water nexus via renewable wind and solar power generation, and carbon capture and storage. Applied Energy

Volume 235, 1 February 2019, Pages 31-42. https://doi.org/10.1016/j.apenergy.2018.10.087 (Link) change.aspx (accessed March 19, 2017).

[36] Rocha GODA, Anjos JPDOS, Andrade JBDE. Energy trends and the water-energy binomium for Brazil. An Acad Bras Cienc 2015. doi:10.1590/0001-3765201520140560.

[37] Barros N, Cole JJ, Tranvik LJ, Prairie YT, Bastviken D, Huszar VLM, et al. Carbon emission from hydroelectric reservoirs linked to reservoir age and latitude. Nat Geosci 2011;4:593-6. doi:10.1038/ngeo1211.

[38] Bastviken D, Tranvik LJ, Downing JA, Crill PM, Enrich-Prast A, Luyssaert S, et al. Freshwater methane emissions offset the continental carbon sink. Science 2011. doi:10.1126/science.1196808.

[39] Edenhofer O, Sokona Y, Seyboth K, Eickemeier P, Matschoss P, Hansen G, et al. Renewable energy sources and climate change mitigation. IPCC Spec. Rep. Renew. Energy Sources Clim. Chang. Mitig., 2011. doi:10.5860/CHOICE.49-6309.

[40] Mekonnen MM, Hoekstra AY. The blue water footprint of electricity from hydropower. Hydrol Earth Syst Sci 2012. doi:10.5194/hess-16-179-2012.

[41] Torcellini PA, Long N, Judkoff RD. Consumptive water use for US power production. NREL 2003.

[42] Intergovernmental Panel on Climate Change. Climate change 2013: The physical science basis. Clim Chang 2013 - They Phys Sci Basis 2013.

[43] Li X, Feng K, Siu YL, Hubacek K. Energy-water nexus of wind powering China: The balancing act between CO2 emissions and water consumption. Energy Policy 2012.

[44] Siddiqi A, Anadon LD. The water-energy nexus in Middle East and North Africa. Crossroads Pathways Renew Nucl Energy Policy North Africa 2011. doi:http://dx.doi.org/10.1016/j.enpol.2011.04.023.

[45] Stokes J, Horvath A. Life Cycle Energy Assessment of Alternative Water Supply Systems (9 pp). Int J Life Cycle Assess 2006;11:335-43. doi:10.1065/lca2005.06.214.

[46] Scott CA, Pierce SA, Pasqualetti MJ, Jones AL, Montz BE, Hoover JH. Policy and institutional dimensions of the water-energy nexus. Energy Policy 2011. doi:10.1016/j.enpol.2011.08.013.

[47] Global Water Intelligence (GWI). A Market Report Worth Its Salt: Desalination Markets 20102011. https://www.globalwaterintel.com/market-report-worth-its-salt-desalination-markets-2010/ (accessed March 19, 2017).

[48] Ghaffour N, Missimer TM, Amy GL. Technical review and evaluation of the economics of water desalination: Current and future challenges for better water supply sustainability. Desalination 2013;309:197-207. doi:10.1016/j.desal.2012.10.015.

[49] Subramani A, Badruzzaman M, Oppenheimer J, Jacangelo JG. Energy minimization strategies and renewable energy utilization for desalination: A review. Water Res 2011;45:1907-20. doi:10.1016/j.watres.2010.12.032.

[50] Elimelech M, Phillip WA. The Future of Seawater Desalination: Energy, Technology, and the Environment. Science (80- ) 2011;333:712-7. doi:10.1126/science.1200488.

[51] Marsh DM. The water-energy nexus: A comprehensive analysis in the context of New South Wales. University of Technology Sydney, 2008.

[52] Gori R, Jiang L-M, Sobhani R, Rosso D. Effects of soluble and particulate substrate on the carbon and energy footprint of wastewater treatment processes. Water Res 2011;45:5858-72. doi:10.1016/j.watres.2011.08.036.

[53] Schnoor JL. Water-Energy Nexus. Environ Sci Technol 2011;45:5065. doi:10.1021/es2016632.

[54] Venkatesh G, Chan A, Bratteb $\varnothing$ H. Understanding the water-energy-carbon nexus in urban water utilities: Comparison of four city case studies and the relevant influencing factors. Energy 2014;75:15366. doi:10.1016/j.energy.2014.06.111.

[55] Curtis TP. Low-Energy Wastewater Treatment: Strategies and Technologies. In: Mitchell R, Gu J-D, editors. Environ. Microbiol. Second Edi, Hoboken, NJ, USA: John Wiley \& Sons, Inc.; 2010. doi:10.1002/9780470495117.ch13.

[56] Kenway SJ, Lant PA, Priestley A, Daniels P. The connection between water and energy in cities: a review. Water Sci Technol 2011;63:1983-90. doi:10.2166/wst.2011.070.

[57] Plappally AK, Lienhard V JH. Energy requirements for water production, treatment, end use, reclamation, and disposal. Renew Sustain Energy Rev 2012;16:4818-48. doi:10.1016/j.rser.2012.05.022.

[58] Sharma AK, Grant AL, Grant T, Pamminger F, Opray L. Environmental and economic assessment of urban water services for a greenfield development. Environ Eng Sci 2009;26:921-34.

[59] Voinov A, Cardwell H. The Energy-Water Nexus: Why Should We Care? J Contemp Water Res Educ 2009;143:17-29. doi:10.1111/j.1936-704X.2009.00061.x.

[60] Griffiths-Sattenspiel B, Wilson W. The Carbon Footprint of Water. 2009.

[61] Wu J, Yan J, Desideri U, Deconinck G, Madsen H, Huitema G, et al. Synergies between energy supply networks. Appl Energy 2017;192:263-7. doi:10.1016/j.apenergy.2017.02.038. 
This article should be cited as: Mahdi Sharifzadeh, Raymond Khoo Teck Hien, Nilay Shah. China's roadmap to low-carbon electricity and water: Disentangling greenhouse gas (GHG) emissions from electricity-water nexus via renewable wind and solar power generation, and carbon capture and storage. Applied Energy

Volume 235, 1 February 2019, Pages 31-42. https://doi.org/10.1016/j.apenergy.2018.10.087 (Link)

[62] Antonelli M, Desideri U, Franco A. Effects of large scale penetration of renewables: The Italian case in the years 2008-2015. Renew Sustain Energy Rev 2017. doi:10.1016/j.rser.2017.08.081.

[63] Fernández-Blanco R, Kavvadias K, Hidalgo González I. Quantifying the water-power linkage on hydrothermal power systems: A Greek case study. Appl Energy 2017;203:240-53.

[64] DeNooyer TA, Peschel JM, Zhang Z, Stillwell AS. Integrating water resources and power generation: The energy-water nexus in Illinois. Appl Energy 2016;162:363-71. doi:10.1016/j.apenergy.2015.10.071.

[65] Abegaz BW, Datta T, Mahajan SM. Sensor technologies for the energy-water nexus - A review. Appl Energy 2017. doi:10.1016/j.apenergy.2017.01.033.

[66] Chen S, Chen B. Urban energy - water nexus : A network perspective. Appl Energy 2016;184:905-14. doi:10.1016/j.apenergy.2016.03.042.

[67] Duan C, Chen B. Energy-water nexus of international energy trade of China. Appl Energy 2017;194:725-34. doi:10.1016/j.apenergy.2016.05.139.

[68] Yu F, Chen J, Sun F, Zeng S, Wang C. Trend of technology innovation in China's coal-fired electricity industry under resource and environmental constraints. Energy Policy 2011;39:1586-99. doi:10.1016/j.enpol.2010.12.034.

[69] Dai J, Wu S, Han G, Weinberg J, Xie X, Wu X, et al. Water-energy nexus: A review of methods and tools for macro-assessment. Appl Energy 2017;210:0-1. doi:10.1016/j.apenergy.2017.08.243.

[70] Wang S, Cao T, Chen B. Water-energy Nexus in China's Electric Power System. Energy Procedia, 2017. doi:10.1016/j.egypro.2017.03.828.

[71] Qin Y, Curmi E, Kopec GM, Allwood JM, Richards KS. China's energy-water nexus - assessment of the energy sector's compliance with the "3 Red Lines" industrial water policy. Energy Policy 2015;82:131-43. doi:10.1016/J.ENPOL.2015.03.013.

[72] Jiang D, Ramaswami A. The "thirsty" water-electricity nexus: Field data on the scale and seasonality of thermoelectric power generation's water intensity in China. Environ Res Lett 2015. doi:10.1088/17489326/10/2/024015.

[73] Pan L, Liu P, Ma L, Li Z. A supply chain based assessment of water issues in the coal industry in China. Energy Policy 2012;48:93-102.

[74] Zhang C, Anadon LD. Life Cycle Water Use of Energy Production and Its Environmental Impacts in China. Environ Sci Technol 2013. doi:10.1021/es402556x.

[75] Bojarski AD, Laínez JM, Espuña A, Puigjaner L. Incorporating environmental impacts and regulations in a holistic supply chains modeling: An LCA approach. Comput Chem Eng 2009;33:1747-59. doi:10.1016/j.compchemeng.2009.04.009.

[76] Chong FK, Lawrence KK, Lim PP, Poon MCY, Foo DCY, Lam HL, et al. Planning of carbon capture storage deployment using process graph approach. Energy 2014;76:641-51. doi:10.1016/j.energy.2014.08.060.

[77] Foo DCY, Tan RR, Lam HL, Abdul Aziz MK, Klemeš JJ. Robust models for the synthesis of flexible palm oil-based regional bioenergy supply chain. Energy 2013;55:68-73. doi:10.1016/j.energy.2013.01.045.

[78] Guillén-Gosálbez G, Grossmann IE. Optimal design and planning of sustainable chemical supply chains under uncertainty. AIChE J 2009;55:99-121. doi:10.1002/aic.11662.

[79] HUGO A, RUTTER P, PISTIKOPOULOS S, AMORELLI A, ZOIA G. Hydrogen infrastructure strategic planning using multi-objective optimization. Int J Hydrogen Energy 2005;30:1523-34. doi:10.1016/j.ijhydene.2005.04.017.

[80] Lam HL, Klemeš JJ, Varbanov PS, Kravanja Z. P-Graph Synthesis of Open-Structure Biomass Networks. Ind Eng Chem Res 2013;52:172-80. doi:10.1021/ie301184e.

[81] Mele FD, Kostin AM, Guillén-Gosálbez G, Jiménez L. Multiobjective Model for More Sustainable Fuel Supply Chains. A Case Study of the Sugar Cane Industry in Argentina. Ind Eng Chem Res 2011;50:4939-58. doi:10.1021/ie101400g.

[82] Pinto-Varela T, Barbosa-Póvoa APFD, Novais AQ. Supply Chain Network Optimization with Environmental Impacts. In: Pistikopoulos EN, Georgiadis MC, Kokossis AC, editors. Comput. Aided Chem. Eng., Lisbon, Portugal: Elsevier; 2011, p. 1155-9.

[83] Pozo C, Ruíz-Femenia R, Caballero J, Guillén-Gosálbez G, Jiménez L. On the use of Principal Component Analysis for reducing the number of environmental objectives in multi-objective optimization: Application to the design of chemical supply chains. Chem Eng Sci 2012;69:146-58. doi:10.1016/j.ces.2011.10.018.

[84] Shabani N, Sowlati T, Ouhimmou M, Rönnqvist M. Tactical supply chain planning for a forest biomass power plant under supply uncertainty. Energy 2014;78:346-55. doi:10.1016/j.energy.2014.10.019.

[85] You F, Tao L, Graziano DJ, Snyder SW. Optimal design of sustainable cellulosic biofuel supply chains: 
This article should be cited as: Mahdi Sharifzadeh, Raymond Khoo Teck Hien, Nilay Shah. China's roadmap to low-carbon electricity and water: Disentangling greenhouse gas (GHG) emissions from electricity-water nexus via renewable wind and solar power generation, and carbon capture and storage. Applied Energy

Volume 235, 1 February 2019, Pages 31-42. https://doi.org/10.1016/j.apenergy.2018.10.087 (Link) Multiobjective optimization coupled with life cycle assessment and input-output analysis. AIChE J 2012;58:1157-80. doi:10.1002/aic.12637.

[86] You F, Wang B. Life Cycle Optimization of Biomass-to-Liquid Supply Chains with DistributedCentralized Processing Networks. Ind Eng Chem Res 2011;50:10102-27. doi:10.1021/ie200850t.

[87] Zamboni A, Bezzo F, Shah N, Bezzo F. Spatially Explicit Static Model for the Strategic Design of Future Bioethanol Production Systems. 2. Multi-Objective Environmental Optimization. Energy \& Fuels 2009;23:5134-43. doi:10.1021/ef9004779.

[88] Zamboni A, Murphy RJ, Woods J, Bezzo F, Shah N. Biofuels carbon footprints: Whole-systems optimisation for GHG emissions reduction. Bioresour Technol 2011;102:7457-65. doi:10.1016/j.biortech.2011.05.020.

[89] Stanway D. Beijing vows 30 percent cut in coal use in 2017 to fight smog. Reuters 2017.

[90] Sharifzadeh M. Integration of process design and control: A review. Chem Eng Res Des 2013;91:251549. doi:10.1016/j.cherd.2013.05.007.

[91] Sharifzadeh M, Thornhill NFNF. Integrated design and control using a dynamic inversely controlled process model. Comput Chem Eng 2013;48:121-34. doi:10.1016/j.compchemeng.2012.08.009.

[92] Sharifzadeh M. Implementation of a steady-state inversely controlled process model for integrated design and control of an ETBE reactive distillation. Chem Eng Sci 2013;92:21-39. doi:10.1016/j.ces.2013.01.026.

[93] Sharifzadeh M, Thornhill NFNF. Optimal selection of control structure using a steady-state inversely controlled process model. Comput Chem Eng 2012;38:126-38. doi:10.1016/j.compchemeng.2011.12.007. 